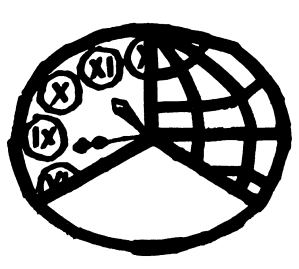

\title{
EL YACIMIENTO DE VALVERDE (MONFORTE DE LEMOS, LUGO, GALICIA, ESPAÑA) Y LAS PRIMERAS EVIDENCIAS DE POBLAMIENTO EN EL PLENIGLACIAL DEL NO DE LA PENÍNSULA IBÉRICA
}

\author{
The archaeological site of Valverde (Monforte de Lemos, Lugo, \\ Spain) and the first evidences of human settlement in NW Iberia \\ during the LGM
}

\author{
Arturo de Lombera Hermida ${ }^{1,2,3}$, Xose-Pedro Rodríguez Álvarez ${ }^{1,2}$, Xose Rabuñal \\ Gayo $^{3}$, Alicia Ameijenda Iglesias ${ }^{3}$, Fátima Martínez Gómez ${ }^{3}$, Miguel Soares \\ Remiseiro ${ }^{3}$, Augusto Pérez Alberti ${ }^{4}$ y Ramón Fábregas Valcarce ${ }^{3}$
}

Recibido el 12 de marzo de 2013. Aceptado el 21 de mayo de 2013

Resumen. El yacimiento de Valverde se emplaza en una ladera del Monte de Valverde, en las proximidades de una de las entradas naturales a la Depresión de Monforte de Lemos (Lugo, Galicia, España).Tras el hallazgo de industria lítica en superficie, se realizaron varios sondeos y prospecciones durante las campañas 2007-2009, recuperando más de 2400 artefactos. El conjunto lítico se caracteriza por la presencia de cadenas operativas expeditivas sobre cuarzos y cuarcitas de mediana calidad. Por otro lado, la producción de láminas y laminillas se centra en el cristal de roca y la cuarcita de grano fino, esta última procedente de afloramientos localizados a $8 \mathrm{~km}$ al SO. Aunque escasos, el uso de sílex foráneo también está documentado. En base a las cadenas operativas identificadas en el yacimiento y, principalmente, la presencia de foliáceos, se propone una adscripción Solutrense para el conjunto. De este modo, Valverde se convierte en la primera evidencia de poblamiento de grupos de cazadores recolectores durante el Último Máximo Glacial (LGM) en el interior del NO de la Península lbérica.

Palabras clave: NO peninsular, Paleolítico superior, tecnología lítica, puntas solutrenses, ocupación al aire libre, cristal de roca.

Abstract. The archaeological site of Valverde is placed on a slope of the Valverde Mount, near one of the entrances into the basin of Monforte de Lemos (Lugo, Galicia, Spain). After the finding of a lithic scatter a survey was carried out in 2007-2009, yielding more than 2400 implements. The lithic assemblage is characterized by the presence of expedient "chaines operatoires" made on quartz and medium-quality quartzite. On the other

(') Institut Català de Paleoecologia Humana i Evolució Social (IPHES), Marcellli Domingo s/n. Edifici W3, Campus Sescelades, E-43007 Tarragona, Spain.alombera@iphes.cat

(2) Area de Prehistoria, Universitat Rovira i Virgili, Av. Catalunya 35, E-43002 Tarragona, Spain

(3) Grupo de Estudos para a Prehistoria do Noroeste (GEPN). Dpto de Historia I, Universidade de Santiago de Compostela. Praza da Universidade, no 1. E-15782 Santiago de Compostela, Spain.

(4) Laboratorio de Tecnoloxia Ambiental. Instituto de Investigacións Tecnolóxicas. Universidade de Santiago de Compostela. Campus Universitario Sur. E-15782 Santiago de Compostela, Spain 
Arturo de Lombera Hermida, Xose-Pedro Rodriguez Álvarez, Xose Rabuñal Gayo, Alicia Ameijenda Iglesias, Fátima Martínez Gómez, Miguel Soares Remiseiro, Augusto Pérez Alberti y Ramón Fábregas Valcarce

hand, blade and microblade blanks are produced on rock crystal and fine-grained quartzite, the latter from outcrops located $8 \mathrm{~km}$ to the SW. Although scarce, the use of allochthonous flint is also attested. Based on the reduction sequences identified at the site, and namely, on the presence of broken leaf points, a Solutrean adscription for this assemblage is proposed, therefore becoming the first evidence of LGM settlement in the inner part of NW Iberia.

Keywords: NW Iberia, Upper Paleolithic, lithic technology, Solutrean points, open-air site, rock crystal.

\section{INTRODUCCIÓN}

La investigación sobre el Paleolítico superior en el NO peninsular, discontinua e irregular, parte de unos sesgos geográficos y conceptuales condicionados tanto por la demarche investigadora como por las características del registro arqueológico (hegemonía de restos líticos) y la fuerte incidencia de los procesos postdeposicionales (Fábregas y de Lombera 2010).

En las décadas centrales del siglo XX la ausencia de tecnocomplejos similares a los franco-cantábricos fueron tentativamente explicados aludiendo a particularidades morfotipológicas de los conjuntos líticos (vg. Camposanquiense), o procesos morfogenéticos y cambios eustáticos que habrian provocado la desaparición de los rellenos contemporáneos a este periodo (Blázquez y Bouza 1952). Si bien las investigaciones sistemáticas sobre el Paleolítico superior arrancan en la década de los años 70 con los trabajos de Ramil Soneira, la continuación de éstos desde el Museo Arqueolóxico de Vilalba establece, a finales de la década de los 90, el marco cronocultural del poblamiento del Paleolítico superior en el NO peninsular (Fábregas y de Lombera 2010; Villar 1997; Ramil y Ramil 1996). Sin embargo, la investigación se ha focalizado en un área geográfica concreta del territorio (Terra Chá, Xistral y Sierras Orientales) quedando grandes vacios, especialmente en el tramo sur y litoral. En el estado actual de conocimiento, esta circunstancia debe responder a una disimetría en la intensidad investigadora más que a un vacio poblacional real, tal y como los recientes trabajos de prospección en áreas inéditas están demostrando (de Lombera et al. 2011; Rodríguez et al. 2008). Del mismo modo, los hiatos, saltos y seriaciones identificados en la secuencia de yacimientos del Paleolítico superior final/Epipaleolítico podrían ser explicados por las características de los depósitos excavados bajo los abrigos graníticos con secuencias cortas y recientes (normalmente con un único nivel de ocupación), muy sensibles a los procesos erosivos propios de esa clase de yacimientos en los que hasta el momento se había concentrado la investigación (Llana et al. 1992).

De acuerdo con el panorama de la investigación a finales del siglo $X X$, en el mapa del Paleolítico superior gallego se marcaba un hiatus que abarcaba, grosso modo, desde el $31000 \mathrm{BP}$ hasta el $15000 \mathrm{BP}$, parte del cual coincidente con el Pleniglacial würmiense (Fábregas y de Lombera 2010). Dado que la investigación se centraba en abrigos y cuevas de las tierras y sierras interiores del NO peninsular, caracterizadas por una mayor rigurosidad climática durante este periodo (Ramil et al. 2005), se podría argumentar una situación análoga a la establecida para la Meseta norte donde no se suponía un poblamiento generalizado de esa región hasta el Tardiglacial (Corchón 2002).

Sin embargo, las recientes intervenciones en Cova Eirós y Cova de Valdavara, situadas en sierras a cotas medias (600-800 m sobre el nivel del mar -s.n.m.-), han aportado evidencias de ocupaciones en momentos inmediatamente previos y posteriores al Último Máximo Glacial (LGM) (Fábregas y de Lombera 2010). En el yacimiento de Cova Eirós, el nivel 1, adscrito al Gravetiense, tiene una datación a techo en torno a 17000 BP (Rodríguez et al. 2011). En la base del talud de Valdavara $1 / 2$ se ha identificado una ocupación datada circa 20000 BP, mientras que para el interior de Valdavara 1 se dispone de una datación para la base de la secuencia de $14630 \pm 70$ BP (Beta-235726) (Fábregas et al. 2011; Vaquero et al. 2009). Estos hallazgos sugieren la posibilidad de un poblamiento más o menos continuado durante el LGM sensu lato en aquellas zonas refugio (valles interiores, franjas litorales), similar al atestiguado en la cornisa cantábrica (Rasilla y Strauss 2007).

El hallazgo en 2007 de una dispersión de industria lítica en la ladera del monte de Valverde, evidenció la presencia de asentamientos al aire libre encuadrables en el Paleolítico superior en las depresiones terciarias del interior gallego. Los sondeos realizados en los años 2009 sacaron a la luz un numeroso conjunto, cuyas características morfotécnicas permitían adscribirlo al tecnocomplejo solutrense. El yacimiento de Valverde se convierte así en la primera referencia de este periodo en el noroeste peninsular, llenando el vacío existente para los asentamientos de esta época entre el valle de Nalón y el valle del Duero portugués. Del mismo modo, corrobora la circulación de grupos humanos en este territorio durante el LGM en una zona refugio del interior gallego.

\section{LAS OCUPACIONES DE LA DEPRESIÓN DE MONFORTE DE LEMOS}

La depresión de Monforte de Lemos (Lugo, Galicia), con una extensión de $175 \mathrm{~km}^{2}$, es una de las principales cuencas sedimentarias de origen tectónico del noroeste de la Penínula Ibérica (Santanach 1994). En realidad, se trata de dos 
subcuencas terciarias separadas por un afloramiento transversal de materiales paleozoicos (Serra do Moncai, Serra de Cubas). El sector noreste de la cuenca es la depresión Bóveda-Brollón mientras que el sector suroeste es la cuenca de Monforte de Lemos strictu sensu. Nuestra investigación se ha centrado en este segundo sector, delimitado al oeste por río Miño y al Sur por el Sil. El río Cabe, afluente del Sil, es la principal corriente fluvial de la cuenca (Fig. 1).

Esta cuenca fue colmatada por aportes terciarios, principalmente arcillas pardas y verdes que se distribuyen en estratos horizontales sobre toda la extensión (origen lacustre). Tras una fase neotectónica y la reorganización de los cursos hidrográficos, sobre el substrato terciario se depositaron los sedimentos pleistocenos, formados principalmente por niveles aluviales de cantos rodados con una potencia de tres a cinco metros, formando una fina película en sus vertientes (Olmo Sanz 1985). El fondo del valle, formado por el río Cabe, apenas supera los 300 m s.n.m.

Los estudios geomorfológicos desarrollados hasta el momento identifican una sucesión de siete niveles, algunos con rellenos pleistocenos, que se asientan sobre las arcillas y arcosas de origen terciario (Ameijenda 2011). Estos niveles han sido definidos en función de su altura media en relación con el curso actual del río Cabe: $\mathrm{N} 1=0 /+5 \mathrm{~m} ; \mathrm{N} 2=+5 /+12.5$ $\mathrm{m} ; \mathrm{N} 3=+12.5 /+20 \mathrm{~m} ; \mathrm{N} 4=+20 /+40 \mathrm{~m} ; \mathrm{N} 5=+40 /+60 \mathrm{~m}$; $\mathrm{N} 6=+60 /+80 \mathrm{~m}$ y $\mathrm{N} 7>+80 \mathrm{~m}$ (Fig. 1).

\subsection{Las prospecciones de Monforte de Lemos}

La mayoría de los programas de investigación sobre el Paleolítico en el noroeste peninsular se han centrado en la cuenca baja del Miño (comarca do Baixo Miño). En el área de la depresión de Monforte, la única referencia a materiales paleolíticos era el hallazgo de un bifaz de cuarcita en Vilaescura a mediados de los años veinte del siglo pasado.

Los numerosos hallazgos realizados desde finales del siglo pasado por un aficionado local (José Antonio Peña) señalaron la importancia de los asentamientos paleolíticos en la cuenca, lo que llevó al inicio de un programa de investigación (Fábregas et al. 2007; de Lombera et al. 2008; Rodríguez

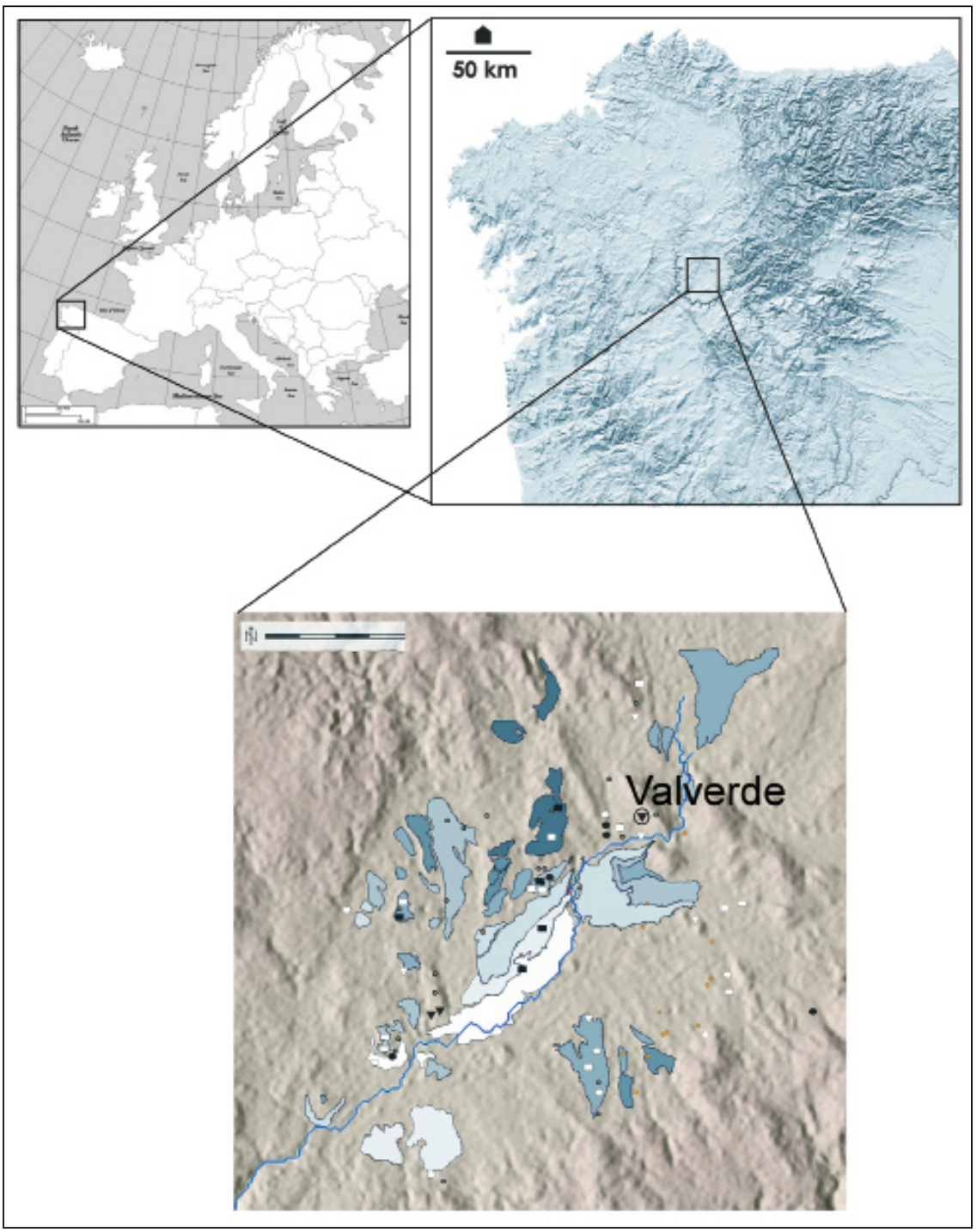

Figura 1. Localización de la depresión de Monforte de Lemos y de los yacimientos paleolíticos. Cuadrados: yacimientos del Paleolítico inferior. Círculos: yacimientos del Paleolítico medio. Triángulos: yacimientos del Paleolítico superior. Puntos: hallazgos aislados. Los signos en negro indican una mayor densidad de artefactos. 
Arturo de Lombera Hermida, Xose-Pedro Rodriguez Álvarez, Xose Rabuñal Gayo, Alicia Ameijenda Iglesias, Fátima Martínez Gómez, Miguel Soares Remiseiro, Augusto Pérez Alberti y Ramón Fábregas Valcarce

et al. 2008). Las prospecciones arqueológicas realizadas en el periodo 2006-2010, permitieron localizar más de un centenar de concentraciones líticas con diferentes densidades de restos. Los materiales recuperados evidencian ocupaciones que abarcan desde el Paleolítico inferior al Paleolítico superior (de Lombera et al. 2011; Rodríguez et al. 2008).

Junto con las prospecciones arqueológicas, se realizaron algunos sondeos en lugares donde la densidad de artefactos en superficie podría indicar la presencia de sitios arqueológicos en contexto estratigráfico. Estos trabajos se llevaron a cabo en los lugares de As Lamas y Valverde en la cuenca de Monforte, y Pedras en la penillanura granítica de 0 Saviñao, proporcionando el hallazgo de conjuntos líticos en contexto estratigráfico (Fábregas et al. 2009; 2010). Además, se realizaron otros hallazgos en contexto estratigráfico en los sitios de 0 Regueiral, y Áspera (Monforte de Lemos) (Fábregas et al. 2007; Rodríguez et al. 2008), que proporcionan más datos sobre las características sedimentarias, tecnológicas y cronológicas de las superficies cuaternarias de la depresión de Monforte (Ameijenda et al. 2010).

\subsection{Localización del yacimiento y tipo de emplazamiento}

Al noreste de la ciudad de Monforte de Lemos, formando parte del conjunto de superficies Precámbricas y Paleozoicas que componen la Serra de Moncai, se encuentra el monte de Valverde.

El yacimiento al aire libre de Valverde está emplazado en un pequeño rellano, a media ladera (380 m s.n.m.) de la vertiente SO del monte del mismo nombre. Debido a los trabajos de apertura de una pista forestal, en el año 2007 fueron recuperados un total de 75 artefactos en superficie. La concentración espacial de los hallazgos, circunscritos a la superficie del rellano (de unos 100 metros cuadrados), la ausencia de rodamiento en las aristas de las piezas y la presencia de restos de talla de pequeñas dimensiones (menores de $0,5 \mathrm{~cm}$ ) permiten plantear la hipótesis de la existencia de un yacimiento en posición primaria o in loco (Rodríguez et al. 2008; Fábregas et al. 2008). Dada la densidad de materiales, en los años subsiguientes se limpiaron cortes estratigráficos y se excavaron dos pequeños sondeos, alcanzando una superficie total de $8 \mathrm{~m}^{2}$. Estas intervenciones permitieron recuperar un conjunto lítico que supera los dos millares de piezas, de las cuales el 88\% de las mayores de $10 \mathrm{~mm}$ fueron encontradas en contexto estratigráfico. Las características morfotécnicas de los materiales y la representación de las variedades líticas muestran una gran homogeneidad en relación con los materiales recuperados en 2007.

Desgraciadamente, el conjunto lítico, aunque en un buen estado de conservación, se encuentra asociado a un horizonte removido por las actividades agrícolas lo que complica la obtención de dataciones absolutas en este yaci- miento. Si bien durante la excavación se han definido varios niveles estratigráficos con el objetivo de ver si se podrian identificar diferentes niveles arqueológicos, dadas las características sedimentarias se constata que los materiales proceden de una remoción in situ de los mismos. La gran homogeneidad a nivel tecnológico y tafonómico de los mismos nos hace descartar la posibilidad de que el conjunto lítico sea fruto de varios momentos culturales distintos.

La estratigrafía de Valverde ha sido definida en función del perfil Este de la Cata II (Fig. 2). En este perfil, con $52 \mathrm{~cm}$ de potencia, se distinguen los siguientes niveles, de muro a techo:

\section{Nivel IA:}

Nivel de $10 \mathrm{~cm}$ de potencia máxima y $3 \mathrm{~cm}$ de potencia mínima. Nivel limo-arcilloso en el que resaltan gravas de cuarzo y cuarcita de entre $1-10 \mathrm{~mm}$ y algún clasto aislado de los mismos materiales de entre $30-100 \mathrm{~mm}$ que se distribuyen sin ninguna ordenación aparente. Tanto las gravas como los clastos son angulosos y subangulosos.

La estratificación de este nivel es paralela-onduladadiscontinua. Presenta bioturbación. Contacto inferior gradual y difuso. Se interpreta como la capa vegetal-suelo superficial.

\section{Nivel IB:}

Nivel de $15 \mathrm{~cm}$ de potencia máxima y de $3 \mathrm{~cm}$ de potencia mínima. Nivel limoso más cementado que en el nivel suprayacente en el que sobresalen un mayor número de gravas de cuarzo y cuarcita, angulosas y subangulosas de entre 1-10 mm. En este nivel apareció industria lítica adscrita al Paleolítico superior y algún fragmento de cerámica. Esto señala que estamos ante un nivel de sedimento removido. En el límite inferior del nivel, en la parte norte del sondeo, se definió una unidad arqueológica (UA-1) compuesta por clastos de entre 30-100 mm de cuarzo y cuarcita, angulosos y subangulosos. Asociado a esta UA-1 apareció la mayor concentración de material arqueológico. Estratificación paralela-ondulada-discontinua. Presenta bioturbación. Contactos superior e inferior graduales y difusos.

\section{Nivel II:}

Nivel de $40 \mathrm{~cm}$ de potencia máxima y $30 \mathrm{~cm}$ de potencia mínima. Matriz limo-arcillosa con gravas de entre 1-10 mm y clastos de cuarzo y cuarcita, angulosos y subangulosos con dimensiones entre 30-60 mm. Sigue apareciendo industria lítica asociada al Paleolítico superior con algún fragmento de cerámica. A pesar de que tanto este nivel como el suprayacente están removidos, destaca el hecho de que en este nivel el número de las piezas arqueológicas se reducen con respecto al nivel IB. Estratificación paralela discontinua. Presenta bioturbación. Contacto superior gradual y difuso. Contacto inferior neto con el depósito de vertiente. 


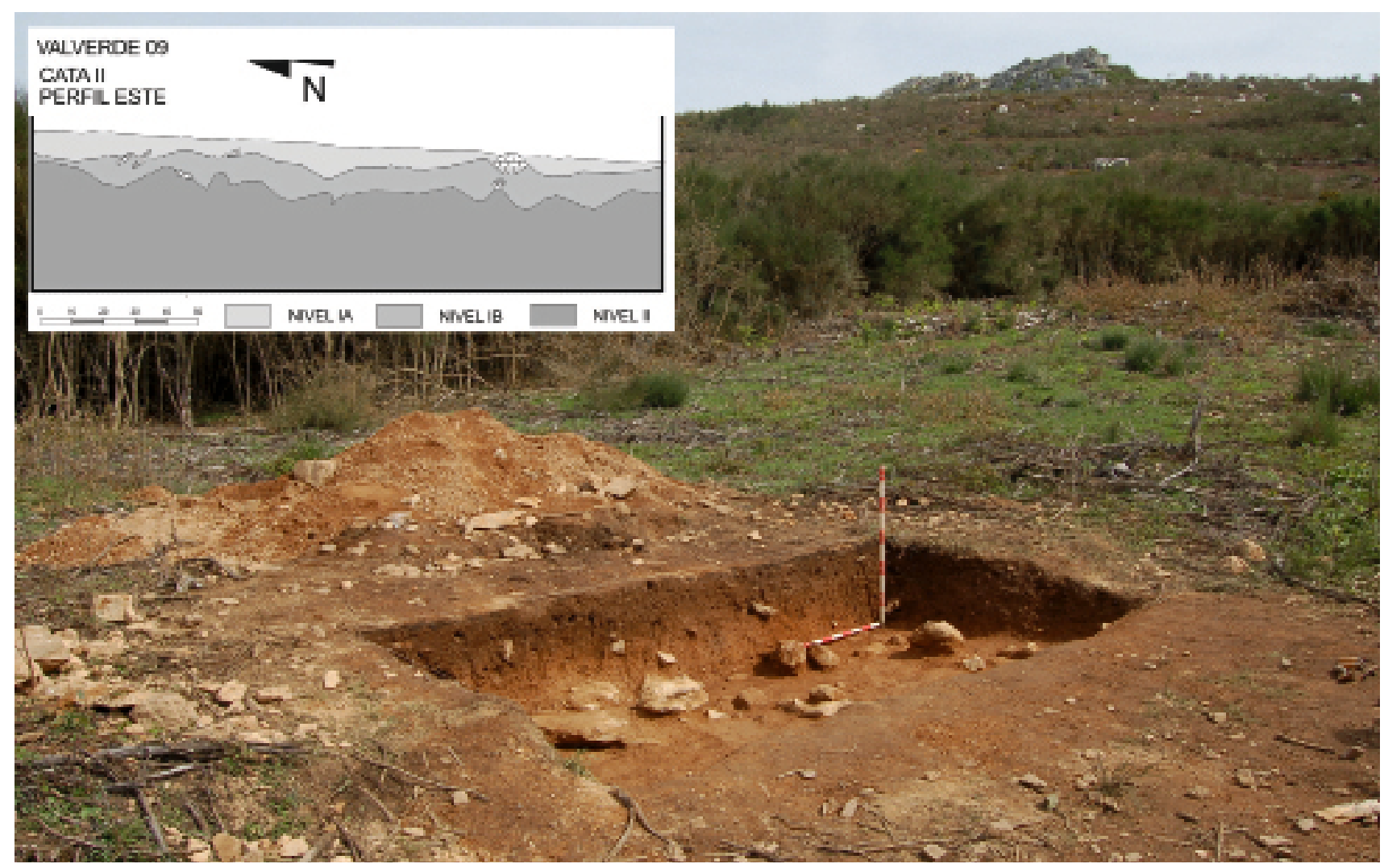

\ FIgURA 2. Emplazamiento del yacimiento de Valverde (Corte del 2008). En dibujo: perfil de la Cata II.

En la base del nivel II de la Cata I y en el corte de la campaña 2008, aparecen grandes bloques de $30-40 \mathrm{~cm}$ de dimensión máxima de la cuarcita del substrato (en la Cata I no se alcanzó), donde se recuperaron también piezas líticas $y$, en este caso, ningún fragmento cerámico. Esta capa se identifica a lo largo de la ladera del monte de Valverde, cuyas caracteristicas responden a un depósito de vertiente de origen periglacial con una matriz limo-arcillosa anaranjada y clastos de cuarcita de $30-50 \mathrm{~cm}$ de eje máximo. Por tanto, la industria lítica aparece a lo largo de toda la secuencia, principalmente en el tercio superior.

Los trabajos agrícolas desarrollados hasta hace pocas décadas habrian producido la remoción in situ de estos materiales, lo que explicaría la aparición de fragmentos cerámicos (10 en total, cuyas dimensiones son menores de $3 \mathrm{~cm}$ ). No obstante, teniendo en cuenta el escasísimo número de éstos, el contexto morfogenético del depósito, las alteraciones postdeposicionales, el hecho de que sólo la industria esté representada en toda la secuencia y, especialmente, que las caracteristicas tecnológicas y tipológicas del conjunto de Valverde difieren substancialmente de los conjuntos de Prehistoria reciente del NO peninsular (Fábregas 1991; Rodríguez 2006), consideramos indudable la naturaleza superopaleolítica del registro lítico de Valverde. La gran homogeneidad tecnológica y tafonómica (sin diferencias de rodamiento o de pátina) de los artefactos recuperados tanto en superficie como en los sondeos, nos sugiere una misma procedencia crono-cultural para todos ellos, si bien la ausencia de una estratigrafía bien preservada nos impide conocer si el conjunto es consecuencia de una o varias ocupaciones en el lugar. Esta problemática sobre las adscripciones cronoculturales de conjuntos al aire libre no es ajena a otros yacimientos peninsulares, pero la coherencia tecnotipológica y los estudios tafonónimos de éstos no arrojan dudas sobre su naturaleza (vg. Tapia et al. 2009; Díez 2000; Delibes y Díez 2006).

\subsubsection{Visibilidad y rutas de acceso naturales}

Su situación en la falda SO del monte, protegido de los vientos dominantes del nordeste, junto con su elevación sobre el fondo del valle convierten a Valverde en un enclave estratégico dentro de la depresión de Monforte, ya que controla visualmente una pequeña vaguada y principal vía de tránsito entre la depresión de Bóveda-Brollón y la depresión de Monforte de Lemos, así como la entrada del Cabe en la depresión monfortina. Su posición elevada sobre la ladera le permite un amplio dominio visual sobre el tercio norte de la depresión de Monforte de Lemos (Rodríguez et al. 2008).

Los análisis de visibilidad realizados mediante herramientas SIG (GRASS v.6.3, con DEM de 30m) nos muestran como desde las tres principales localidades del Paleolítico superior (Valverde, Áspera y Costa Grande - III) se domina visualmente las principales rutas de acceso y tránsito por la depresión monfortina (Fig. 3). Este tipo de emplazamiento 
Arturo de Lombera Hermida, Xose-Pedro Rodriguez Álvarez, Xose Rabuñal Gayo, Alicia Ameijenda Iglesias, Fátima Martínez Gómez, Miguel Soares Remiseiro, Augusto Pérez Alberti y Ramón Fábregas Valcarce

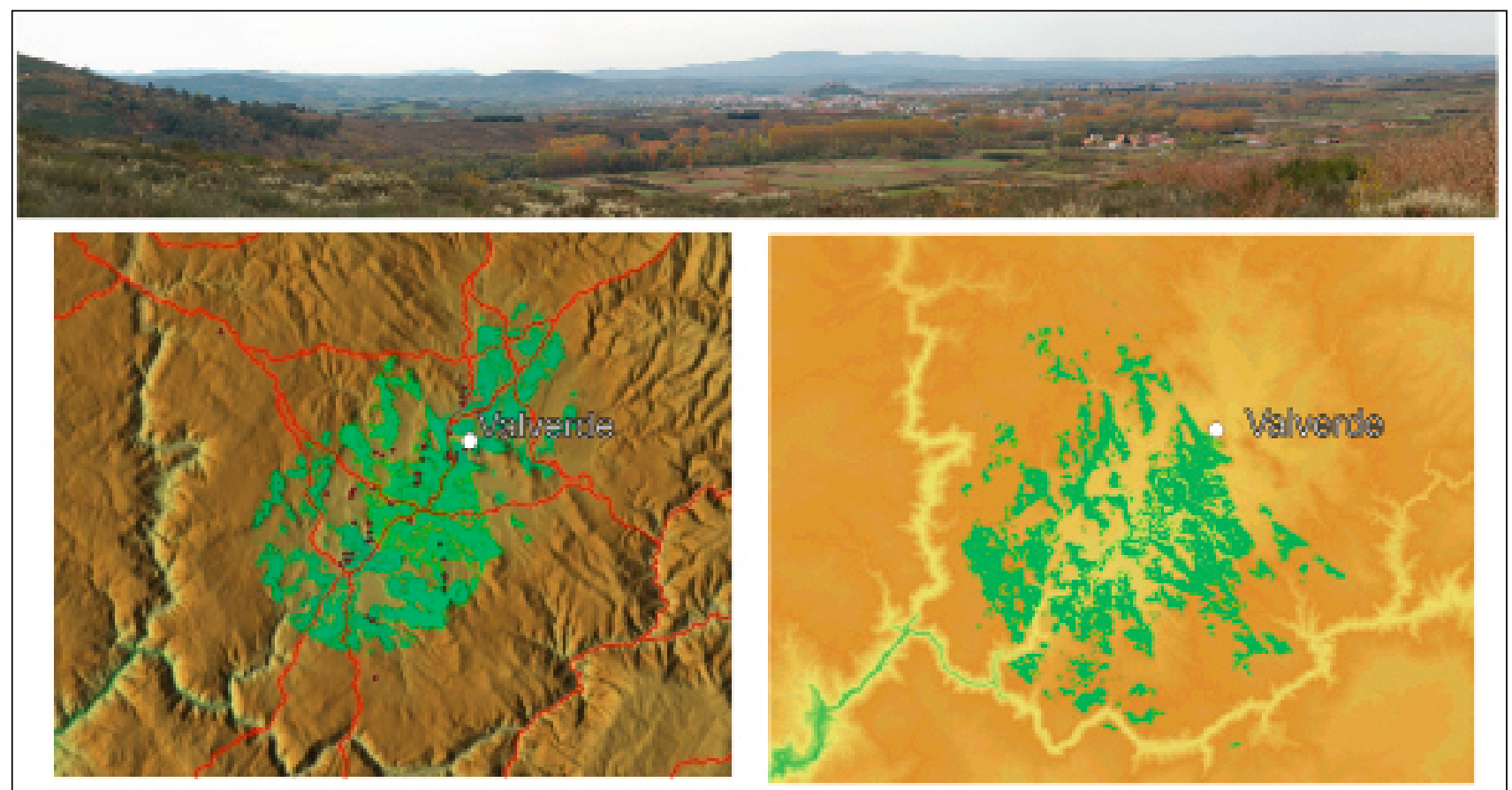

$\Delta$ Figura 3. Panorámica desde el yacimiento (foto) y visibilidad desde los yacimientos del Paleolítico superior sobre las principales rutas de tránsito por la depresión de Monforte de Lemos (izquierda), y desde el yacimiento de Valverde (derecha).

es propio de los asentamientos del Paleolítico superior del NO, donde los criterios de proximidad a cursos y puntos de agua y fuentes de materia prima parecen supeditados a los criterios de control y visibilidad de las principales vías de tránsito (López 2002). La importancia de este enclave de la depresión durante el Paleolítico superior queda remarcada por el hallazgo de una pieza foliácea y un núcleo de cristal de roca en el yacimiento en superficie de 0 Regueiral-III, situado justo en la ladera opuesta al monte de Valverde.

\section{EL CONJUNTO LÍTICO DEL YACIMIENTO DE VALVERDE}

El conjunto lítico del yacimiento de Valverde asciende a un total de 2.434 piezas recuperadas tanto en las prospecciones arqueológicas como en los sondeos realizados en los años 2008 y 2009. Como hemos comentado, los trabajos agrícolas han producido la movilización in situ de los materiales, así como la excavación de la pista forestal ha esparcido por la superficie gran cantidad de materiales, lo que imposibilita obtener un buen contexto estratigráfico, y por ende cronológico, para este yacimiento. No obstante, dada la gran homogeneidad técnica que presentan los diferentes conjuntos (procedentes de las catas o colecciones de superficie), así como la imposibilidad de establecer una diferenciación por niveles, analizaremos todos los elementos en conjunto, conocedores de los condicionantes de cara a realizar inferencias de carácter cronológico y funcional de las ocupaciones.
El conjunto muestra una amplia variedad litológica dominada por las materias primas de carácter local como el cuarzo (56\%), diversas variedades de cuarcita (24\%) y el cristal de roca (6\%), seguidos en menor medida por los materiales criptocristalinos como sílex, liditas y argilitas (Tab. 1). Esta variedad de recursos contrasta con la documentada en los yacimientos del Paleolítico inferior y medio de la misma depresión monfortina, donde dominan las cuarcitas y cuarzos de origen fluvial, marcando una clara ruptura en las estrategias de captación de las comunidades del $\mathrm{Pa}-$ leolítico superior (de Lombera et al. 2008; 2011).

Con respecto a las categorías estructurales, se aprecia la presencia de cadenas operativas completas (representación de todas las categorías, y el gran porcentaje de productos y restos de talla) que indican la existencia de talla in situ de ciertos materiales, aunque el grado de corticalidad de los soportes (5,9\% de cortical dominante) y formato de los núcleos, señalan que muchos de los elementos han sido introducidos como soportes o preformas ya tallados en el yacimiento, especialmente en lo referente a las cuarcitas de grano fino, argilitas, liditas y silex. Este hecho apunta hacia fases avanzadas o finales en la producción de soportes $y$ útiles.

En el conjunto lítico existen diferentes modelos de gestión de las materias primas según su objetivo dentro de las estrategias de producción de soportes líticos: uno basado en la obtención de soportes lascares (cuarzo y cuarcitas locales); otro en la producción microlaminar y laminar (cristal de roca $y$, en menor medida, cuarcita de grano fino); y otro en la configuración de soportes para foliáceos o pequeños 


\begin{tabular}{|c|c|c|c|c|c|c|c|c|c|c|c|c|c|c|c|c|}
\hline \multirow[b]{2}{*}{ Mat. Prima } & \multicolumn{3}{|c|}{$\begin{array}{c}\text { Cantos/ } \\
\text { percutores }\end{array}$} & \multicolumn{4}{|c|}{ Núcleos } & \multicolumn{2}{|c|}{ Objt. retocados } & \multicolumn{5}{|c|}{ Productos de talla } & \multirow[b]{2}{*}{ TOTAL } & \multirow[b]{2}{*}{$\%$} \\
\hline & Bna & Bnb & Bnc & BN1GE & BN2GE & BNE & FBN1G & BN2GC & FBN2G & $\mathrm{BP}$ & BPF & FBP & Frag & $\begin{array}{c}\text { Restos } \\
<10 \mathrm{~mm}\end{array}$ & & \\
\hline Cuarzo & & 1 & & 16 & 5 & 1 & 6 & 58 & 6 & 227 & 163 & 81 & 46 & 747 & 1357 & 55,75 \\
\hline$\%$ & & 0,07 & & 1,18 & 0,37 & 0,07 & 0,44 & 4,27 & 0,44 & 16,73 & 12,01 & 5,97 & 3,39 & 55,05 & & \\
\hline NN & & & & 2 & & 1 & 1 & 24 & 5 & 90 & 61 & 33 & 13 & & & \\
\hline$\%$ & & & & 0,87 & & 0,43 & 0,43 & 10,43 & 2,17 & 39,13 & 26,52 & 14,35 & 5,65 & & & \\
\hline NS & & & & 14 & 5 & & 5 & 32 & 1 & 126 & 97 & 46 & 32 & & & \\
\hline$\%$ & & & & 3,91 & 1,40 & & 1,40 & 8,94 & 0,28 & 35,20 & 27,09 & 12,85 & 8,94 & & & \\
\hline SN & & & & & & & & 1 & 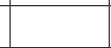 & 6 & 2 & & & & & \\
\hline$\%$ & & & & & & & & 11,11 & & 66,67 & 22,22 & & & & & \\
\hline SS & & & & & & & & & & 1 & 2 & 1 & & & & \\
\hline$\%$ & & & & & & & & & & 25,00 & 50,00 & 25,00 & & & & \\
\hline Indet & & 1 & & & & & & 1 & 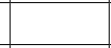 & 4 & 1 & 1 & 1 & & & \\
\hline$\%$ & & 11,11 & & & & & & 11,11 & & 44,44 & 11,11 & 11,11 & 11,11 & & & \\
\hline $\begin{array}{l}\text { Cristal } \\
\text { de roca }\end{array}$ & 1 & & 2 & 23 & & & 2 & 9 & 1 & 32 & 10 & 6 & 5 & 69 & 160 & 6,57 \\
\hline$\%$ & 0,63 & & 1,25 & 14,38 & & & 1,25 & 5,63 & 0,63 & 20,00 & 6,25 & 3,75 & 3,13 & 43,13 & & \\
\hline $\begin{array}{l}\text { Cuarctita } \\
\text { grano fino }\end{array}$ & & & & 4 & 4 & & 3 & 30 & 7 & 130 & 73 & 79 & 9 & 158 & 497 & 20,42 \\
\hline$\%$ & & & & 0,80 & 0,80 & & 0,60 & 6,04 & 1,41 & 26,16 & 14,69 & 15,90 & 1,81 & 31,79 & & \\
\hline Cuarcita & & & 2 & & 2 & & & 5 & 2 & 33 & 12 & 11 & 1 & 19 & 87 & 3,57 \\
\hline$\%$ & & & 2,30 & & 2,30 & & & 5,75 & 2,30 & 37,93 & 13,79 & 12,64 & 1,15 & 21,84 & & \\
\hline Argilita & & & & & 1 & & & 10 & 10 & 21 & 6 & 30 & 3 & 57 & 138 & 5,67 \\
\hline$\%$ & & & & & 0,72 & & & 7,25 & 7,25 & 15,22 & 4,35 & 21,74 & 2,17 & 41,30 & & \\
\hline Sílex & & & & 2 & & & 1 & 13 & 1 & 28 & 13 & 16 & 6 & 37 & 117 & 4,81 \\
\hline$\%$ & & & & 1,71 & & & 0,85 & 11,11 & 0,85 & 23,93 & 11,11 & 13,68 & 5,13 & 31,62 & & \\
\hline Lidita & & & & 1 & 2 & & & 6 & & 6 & 6 & 13 & 2 & 30 & 66 & 2,71 \\
\hline$\%$ & & & & 1,52 & 3,03 & & & 9,09 & & 9,09 & 9,09 & 19,70 & 3,03 & 45,45 & & \\
\hline Sílice & & & & & & & & 1 & & 1 & 2 & 4 & & & 8 & 0,33 \\
\hline$\%$ & & & & & & & & 12,50 & & 12,50 & 25,00 & 50,00 & & & & \\
\hline Hematites & & & & & & & & & & & & 1 & & & 1 & 0,04 \\
\hline$\%$ & & & & & & & & & & & & 100,00 & & & & \\
\hline Otros & & & & & & & & & & & & & & 3 & 3 & 0,12 \\
\hline$\%$ & & & & & & & & & & & & & & 100,00 & & \\
\hline TOTAL & 1 & 1 & 4 & 46 & 14 & 1 & 12 & 132 & 27 & 478 & 285 & 241 & 72 & 1120 & 2434 & \\
\hline$\%$ & $\mid 0,04$ & 0,04 & 0,16 & 1,89 & 0,58 & 0,04 & 0,49 & 5,42 & 1,11 & 19,64 & 11,71 & 9,90 & 2,96 & 46,01 & $\mid 100,00$ & \\
\hline
\end{tabular}

$\Delta$ Tabla 1. Categorias estructurales y materias primas del conjunto de Valverde. Para los cuarzos xenomorfos los grupos definidos según textura y homogeneidad son: NS (No grano, si plano); NN (No grano, no plano); SN (Sí grano, no plano); SS (Sí grano, sí plano). En el análisis tecnológico no se han tenido en cuenta los fragmentos de talla menores de $1 \mathrm{~cm}$, centrándose el estudio sobre un total de 1314 piezas.

retocados (cuarcita de grano fino, silex y argilitas). Consecuentemente, se aprecia una especialización en la gestión de los recursos líticos encaminada a satisfacer las necesidades tecnológicas y funcionales de estos grupos, que se traduce en una amplia variedad de materias primas.

\subsection{Estrategias de abastecimiento de materias primas}

La demanda litológica en el yacimiento de Valverde se satisface principalmente con recursos de carácter local dentro de un radio de 2-5 km como pueden ser los cuarzos, cuarcitas y liditas vinculadas a los afloramientos inmediatos $y$, en menor medida, a los depósitos secundarios del valle del Cabe y abanicos aluviales situados en la base del mismo monte, como indican los mayores porcentajes de neocortex fluvial en cuarcitas y cuarzos $(43,75 \%$ y $18,1 \%$, respectivamente). Dentro de los cuarzos, se observa una escasa variabilidad, centrándose sólo en los tipos macrocristalinos (Grupos morfoestructurales NS y NN). Hay que destacar la alta representación de soportes en cuarzo sin planos internos $(37,7 \%)$ que debe ser entendida como intencional dado que los filones circundantes al yacimiento suelen estar bastante tectonizados. 
Arturo de Lombera Hermida, Xose-Pedro Rodríguez Álvarez, Xose Rabuñal Gayo, Alicia Ameijenda Iglesias, Fátima Martínez Gómez, Miguel Soares Remiseiro, Augusto Pérez Alberti y Ramón Fábregas Valcarce
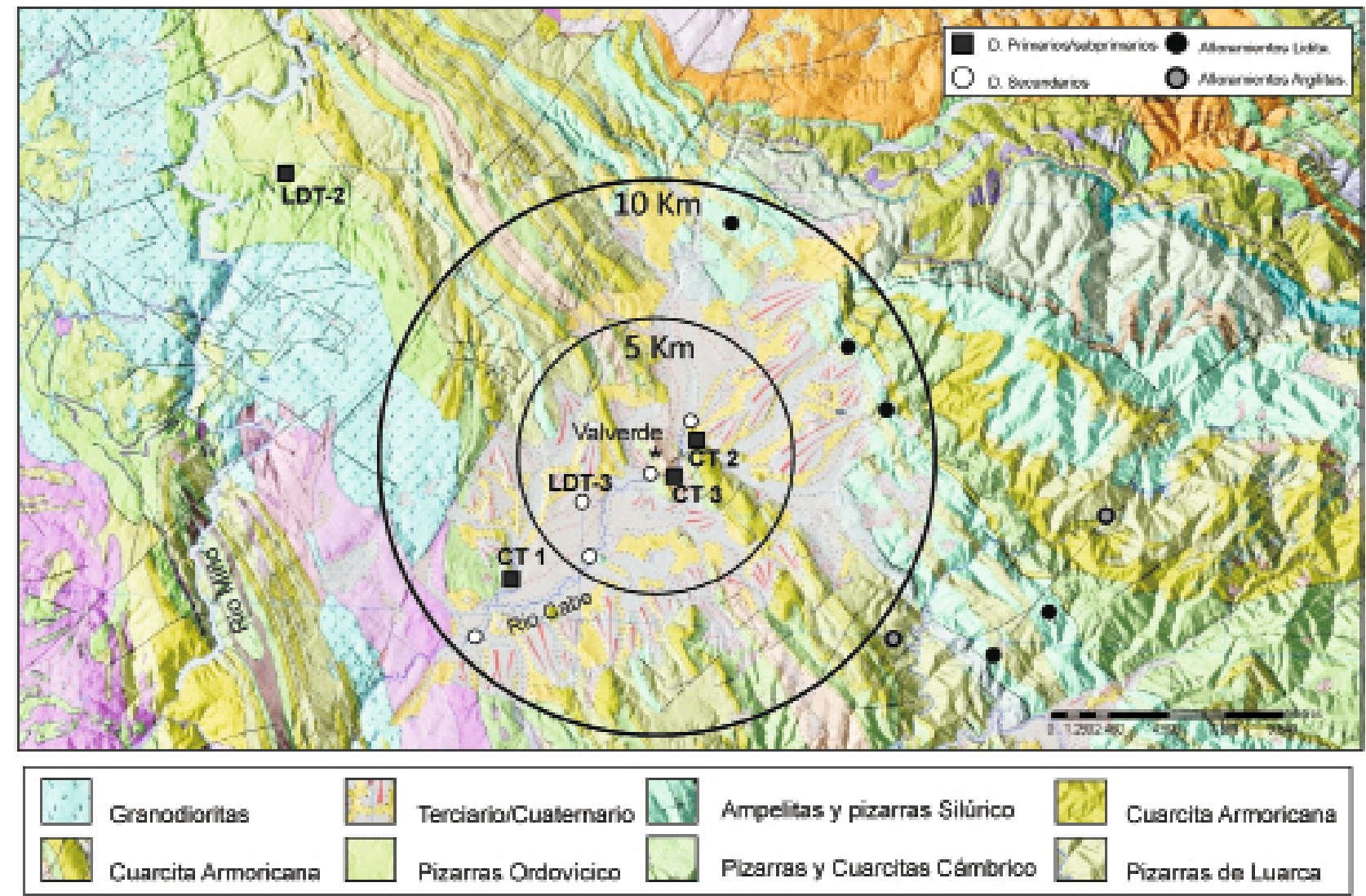

\ Figura 4. Mapa de captación de las principales materias primas en la depresión. CT-1: Cuarcitas de Costa Grande; CT-2: Cuarcitas de Moncai; CT-3: Cuarcitas de Valverde.

Éstos se ven complementados con la explotación de recursos primarios o subprimarios del entorno local más distante (en un radio de $5-15 \mathrm{~km}$ ) como pueden ser las cuarcitas de grano fino. Los estudios preliminares de caracterización mineralógica (Fábregas et al. 2010) han permitido la identificación de dos fuentes de abastecimiento para este tipo de cuarcita. Por un lado, los afloramientos de Costa Grande (Ordovícico), situados a $8 \mathrm{~km}$ al SO del yacimiento, donde han sido identificadas varias dispersiones adscritas al Paleolítico superior interpretadas como talleres de abastecimiento (Costa Grande-II, Costa Grande-III) (Fábregas et al. 2009). Este tipo de cuarcita presenta una granulometría muy fina y un alto grado de cementación, lo que le confiere una fractura concoidal muy homogénea y óptima para la talla. Un subconjunto de estas cuarcitas procede de los afloramientos de cuarcita armoricana de la sierra de Moncai, en las proximidades del monte de Valverde (Fig. 4), cuyas caracteristicas texturales y aptitud para la talla son similares a las definidas anteriormente. Para el cristal de roca, se han definido varios ámbitos, procedentes de drusas y geodas presentes en los filones de cuarzo del propio monte de Valverde, y también entre las cuarcitas de Costa Grande.

Dentro del mismo entorno se encuentran las liditas del Silúrico y silicificaciones (argilitas) de las formaciones de pizarras de Luarca (Ordovícico) descritas al E-NE del yacimiento, ya dentro de la depresión de Bóveda-Brollón, aunque durante las prospecciones (todavia en curso) no se han podido localizar los afloramientos (Fig. 4). Por el tipo de alteración del córtex, estos materiales son de origen primario o subprimario, introducidos en el yacimiento en forma de placas o lascas de mediano formato.

Finalmente, la presencia de silex es muy restringida, pero el escaso número de elementos en este material y el hecho de que se trate de productos finales o productos de acondicionamiento de núcleos o útiles con nula corticalidad nos habla de un modelo de introducción y transformación diferente al de las otras materias primas. Se han identificado hasta 6 variedades de silex con diferentes coloraciones (beige, verdosa, amarillenta, etc.) y grados de opacidad que indican dos tipos principales de ambiente de formación, uno evaporítico y otro marino. La identificación de fósiles de origen marino y arenas en algunos de los subtipos (tipos 3 y 5) nos indica unos contextos no identificados en las formaciones geológicas del NO peninsular, sugiriendo un probable origen cretácico o jurásico (de Lombera et al. e.p.). En base a este hecho, junto a los escasos datos arqueológicos disponibles sobre la movilidad de las sociedades de cazadores recolectores del Paleolítico superior gallego (Fábregas y de 


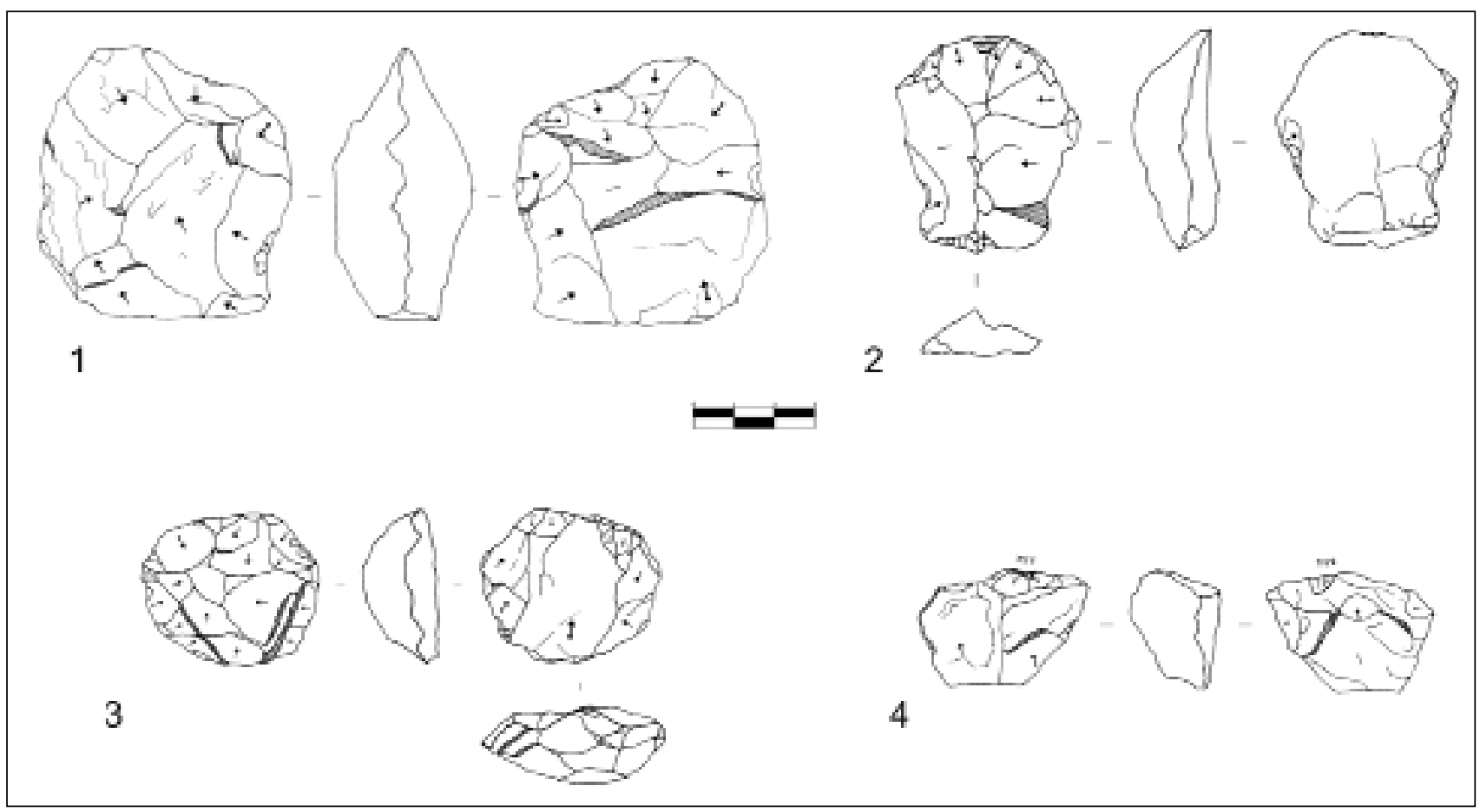

A Figura 5. Núcleos 1-3 centrípetos en cuarzo (1) y cuarcita de grano fino (2,3). 4: Núcleo ortogonal en cuarzo.

Lombera, 2010), planteamos un posible origen cantábrico de estos materiales, coherente con la alta movilidad de los materiales atestiguada para estos periodos (Aubry et al. 2012; Corchón et al. 2009). Por otro lado, los elementos de uno de los tipos de sílex presentan un lustre característico del tratamiento térmico de estos materiales.

En el conjunto lítico de Valverde se observa una intensificación de la explotación de los recursos abióticos patente en el aumento de la variedad litológica con vistas a la aplicación de cadenas operativas especializadas. Este tipo de gestión es similar al atestiguado en el nivel 1 de Cova Eirós (Gravetiense) y preludia el modelo descrito en los conjuntos magdalenienses del norte lucense (de Lombera y Rodríguez 2010; de Lombera et al. e.p.; Villar 1997). Sin embargo, en Valverde se observa un mayor grado de especialización, centrada en la búsqueda y explotación de recursos primarios de cuarcita de grano fino y de muy alta calidad, cuya utilización está principalmente encaminada a la producción de foliáceos. Esta ruptura con respecto a las estrategias de momentos anteriores es análoga a la documentada en otras áreas peninsulares para estos periodos (Conde et al. 2000; Corchón y Cardoso 2005).

\subsection{Estrategias de producción de soportes}

Las estrategias de talla responden a dos cadenas operativas diferenciadas según los objetivos en la producción: soportes lascares o laminares. Para la producción de soportes lascares se aplican unas estrategias más expeditivas basadas en la reducción bifacial de los núcleos mediante series ortogo- nales y centrípetas (Fig. 5). Estas estrategias son aplicadas en las cuarcitas locales y, especialmente, en los cuarzos de peor calidad (grupo NS) mediante series secantes que, en los cuarzos de mayor calidad (NN), acaban originando morfologías discoidales. Un núcleo presenta un esquema de explotación Levallois. El tipo de soportes obtenidos son lascas de pequeño y mediano formato con amplios talones unifacetados $(56,1 \%)$ o bifacetados (15,5\%), y negativos en la cara dorsal con disposiciones unipolares, ortogonales y centripetas.

Sin embargo, dentro de las estrategias de explotación definidas en el yacimiento sobresalen los métodos de talla bipolar y laminar (43,8 y 22,8\% de los núcleos, respectivamente). El método bipolar destaca por su generalización en el conjunto ya que es aplicado sobre todo tipo de materiales, incluido el sílex. Estos núcleos se encuentran en su fase final de explotación, con formatos muy pequeños (promedio $25 \times 23 \times 12 \mathrm{~mm}$ ), lo que nos indica el grado de aprovechamiento de estos materiales (Figs. 6 y 7). Si bien no se han encontrado percutores o yunques con los estigmas de talla propios de esta técnica (de la Torre et al. 2013; Díez et al. 2011), las características morfotécnicas de los productos, los astillados en las aristas de intervención, la presencia de ondas de percusión marcadas y a veces enfrentadas, tanto de núcleos como de lascas, son criterios inequívocos (vg. de la Peña 2011). Los productos son de pequeñas dimensiones con caras ventrales rectilineas y talones astillados lineales 0 puntiformes, pero dotados con buenos filos cortantes. El predominio de estos núcleos en el conjunto (43,8\%), su pequeño formato y el hecho de que algunas lascas hayan sido explotadas como núcleos, nos indican el recurso a esta téc- 
Arturo de Lombera Hermida, Xose-Pedro Rodríguez Álvarez, Xose Rabuñal Gayo, Alicia Ameijenda Iglesias, Fátima Martínez Gómez, Miguel Soares Remiseiro, Augusto Pérez Alberti y Ramón Fábregas Valcarce

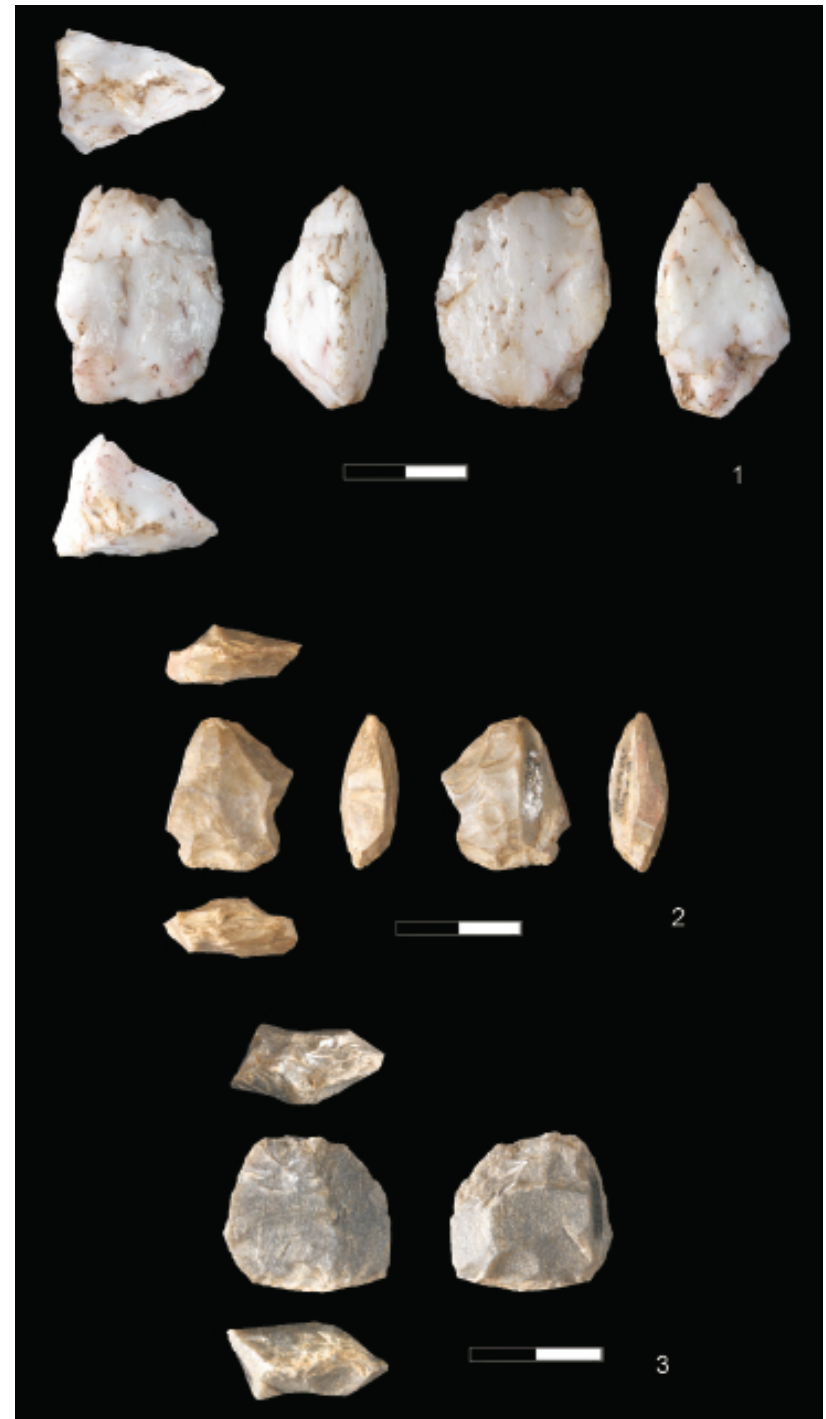

A Figura 6. Ejemplos de núcleos bipolares en cuarzo (1), sílex (2) y cuarcita de grano fino (3).

nica para el máximo aprovechamiento de la materia prima mediante el reciclaje (de la Peña y Vega 2012), si bien en algunos prismas de cristal de roca el objetivo parece ser la producción de pequeñas esquirlas alargadas (vg. Klaric 2009).

La producción de soportes laminares y microlaminares se ha documentado en las cuarcitas de grano fino, el cuarzo y, principalmente, el cristal de roca. Para la cuarcita de grano fino y el cuarzo contamos con fragmentos proximales y mesiales de láminas de secciones trapezoidales y triangulares. Cabe destacar la presencia de dos núcleos sobre fragmentos de cuarzo que presentan en uno de los flancos una serie de levantamientos laminares realizados desde un plano de percusión liso (Fig. 8: 4).

En el cristal de roca se observa una explotación especializada orientada a la obtención de laminillas de hasta $2 \mathrm{~cm}$ de longitud. Para ello, se seleccionan aquellos prismas más homogéneos, mientras que los más alterados o de pequeño formato son explotados mediante talla bipolar. Del mismo modo, la cara de explotación se localiza en la parte más homogénea (hialina) del soporte, ya sea la base 0 , normalmente, el ápice de los mismos (Fig. 8).

Si bien el cristal de roca (o cuarzo automorfo) se caracteriza por la anisotropía en su fractura, los métodos de talla se aprovechan de esta cualidad y de las morfologías naturales del soporte para la obtención de las laminillas (Chelidonio 1990; Novikoz y Radililovsky 1990; Villar 1991; Garcia y Velaz 1997). En el yacimiento de Valverde el aprovechamiento de estos soportes viene determinado por el grosor y homogeneidad de los prismas. En primer lugar, se crea un plano de percusión oblicuo respecto al c-axis del cristal de cuarzo mediante la extracción del ápice. Desde ese plano se realiza una serie de extracciones principales (2-5) que pueden seguir planos oblicuos o paralelos al eje de cristalización. En aquellos prismas más espesos, la explotación continúa a lo largo de la arista (tournante) obteniéndose un mayor número de levantamientos. Se observa una clara jerarquización en el rol de las caras, manteniéndose siempre la explotación unipolar sobre una cara preferente (la más hialina) y nunca alternando roles. En este sentido, el acondicionamiento de los soportes es mínimo ya que aprovechan las aristas de las facetas del prisma como arista guía inicial. Sólo en algunos casos se observa una serie de levantamientos opuesta de cara a crear la convexidad distal en el núcleo que facilite la obtención de levantamientos más profundos y evite el reflejado de los mismos (Fig. 8). Las cadenas operativas sobre cristal de roca en el yacimiento de Valverde están muy estructuradas y estandarizadas, explotando los prismas mediante series cortas hasta agotar la posibilidad de obtener nuevas extracciones (normalmente al alcanzar la mitad del volumen del prisma), o por la aparición de reflejados. Tanto en las caras talonares de algunas laminillas como en las cornisas de los núcleos se observan claros signos de abrasión y preparación de cornisas.

En el conjunto lítico están presentes núcleos y productos pertenecientes a las diferentes fases de explotación (lascas de apertura de planos de percusión, de acondicionamiento de prismas, etc.) lo que indica que la talla de estos productos se realizó in situ. Si bien algunos prismas de pequeñas dimensiones presentan levantamientos oblicuos en la parte distal análogos a los definidos como Útiles de Arista Diédrica (UAD, Fabián, 1984-85), en este caso parecen tratarse de testados o subproductos de las fases iniciales de la reducción. Estos esquemas de explotación laminar de los prismas se encuentran bien representados en el NO peninsular desde, al menos, los momentos gravetienses en el Norte de Portugal (Aubry et al. 2009) continuando a lo largo del Magdaleniense y Epipaleolítico del norte lucense (Villar 1997).

\subsection{Estrategias de configuración}

La presencia de retocados en el conjunto asciende a 159 elementos (6,5\% del total), destacando las raederas y las muescas sobre los raspadores, denticulados, foliáceos, 


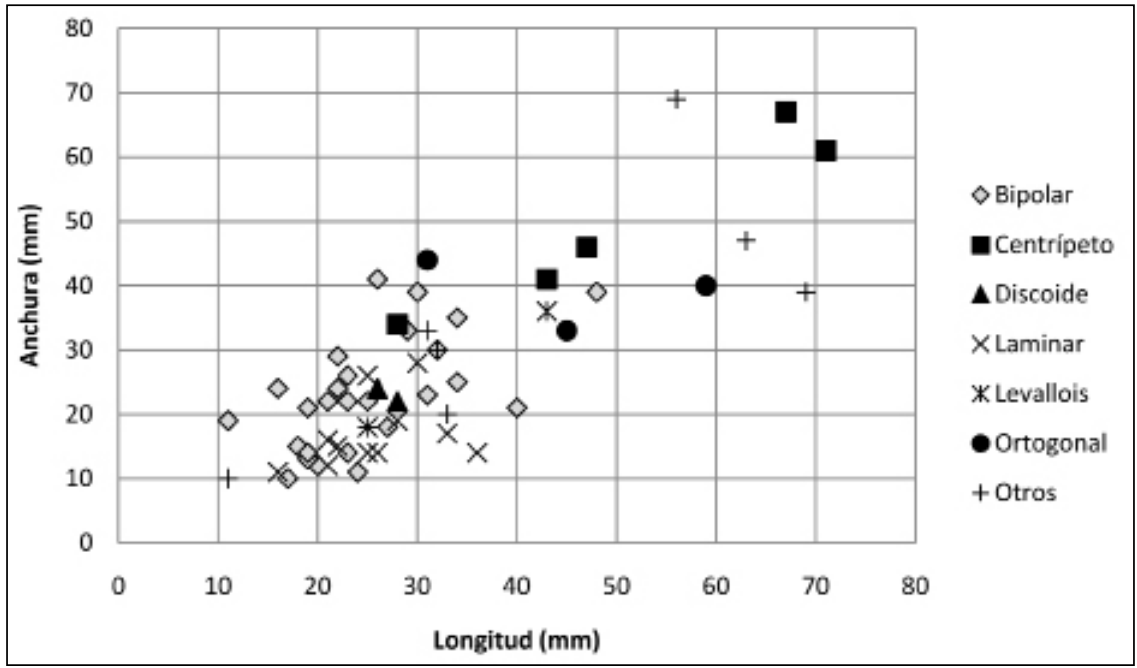

4 Figura 7. Formato de los núcleos según el método de talla.

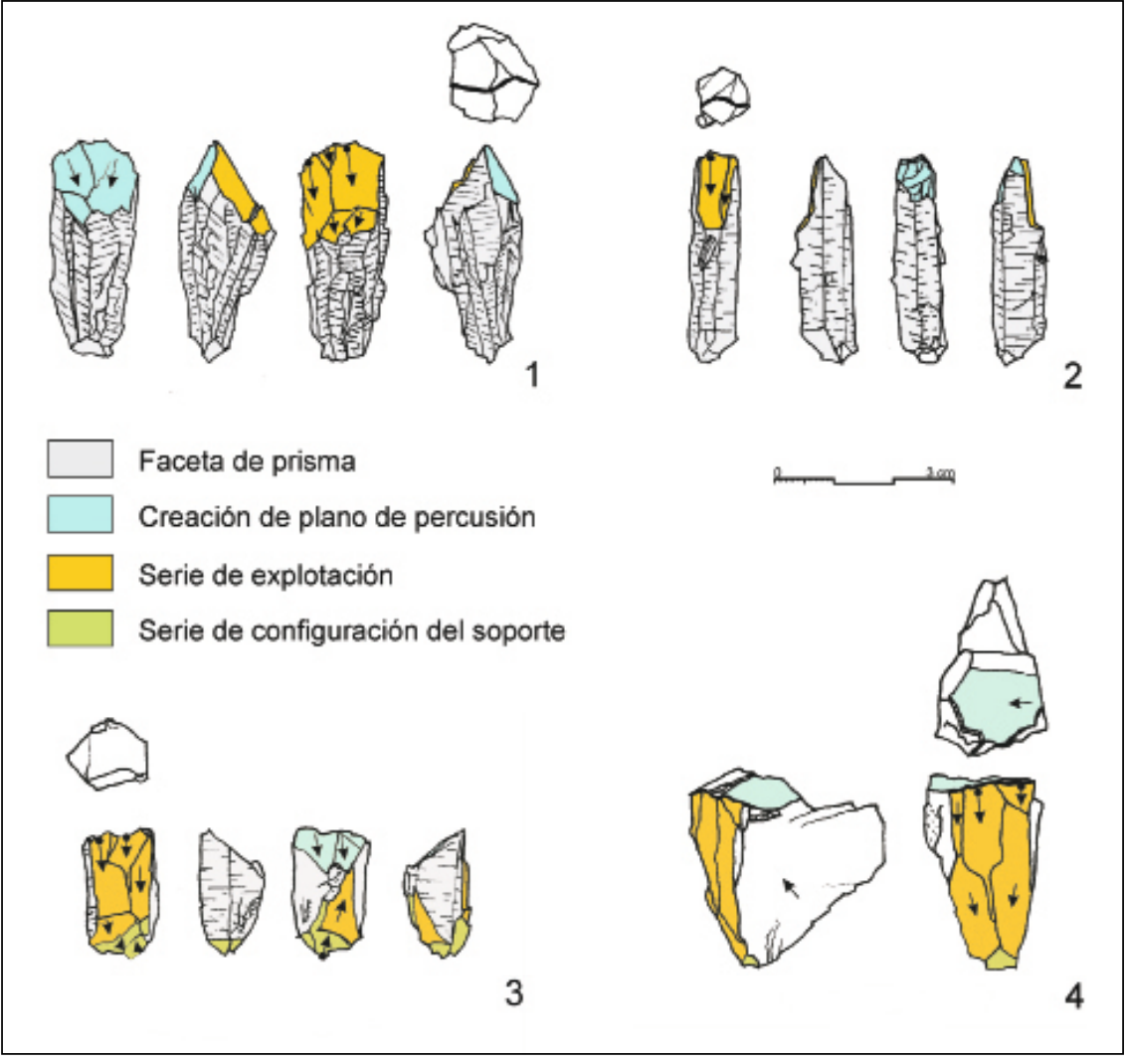

4 Figura 8. Talla laminar en cuarzo (4) y prismas de cristal de roca (1-3). buriles y elementos de dorso o truncadura (Tab. 2), aunque debemos tener en cuenta el alto porcentaje de fragmentos de piezas que presentan retoques marginales en sus laterales. El retoque plano adquiere una importante presencia dentro de los retocados $(11,3 \%)$, estando presente en todas las materias primas salvo el cristal de roca. Para los útiles de substrato se utilizan soportes lascares de medio formato de cuarzo y cuarcita, llegando incluso a reciclar núcleos bipolares o fragmentos de foliáceos gruesos para la elaboración de denticulados y raederas (Fig. 9).

En el grupo de los raspadores destacan los realizados sobre lascas laminares de cuarcita de grano fino cuyos la- terales y aristas centrales presentan intensos desconchados y micropulidos, probablemente fruto de su enmangado. Los raspadores de pequeño formato son más numerosos, realizados sobre pequeñas lascas de sílex. Las series de retoque suelen centrarse en el frente, aunque algunas piezas presentan un leve acondicionamiento de los laterales (Fig. 10).

Dentro de los objetos configurados del conjunto de Valverde destaca la presencia de varios fragmentos proximales y mesiales de puntas de laurel realizados en cuarcita de grano fino, silex, argilitas y cuarzo de buena calidad. Estas puntas de pequeñas dimensiones $(5-7 \mathrm{~cm})$ presentan series de retoque plano paralelos y subparalelos y bases convexas 


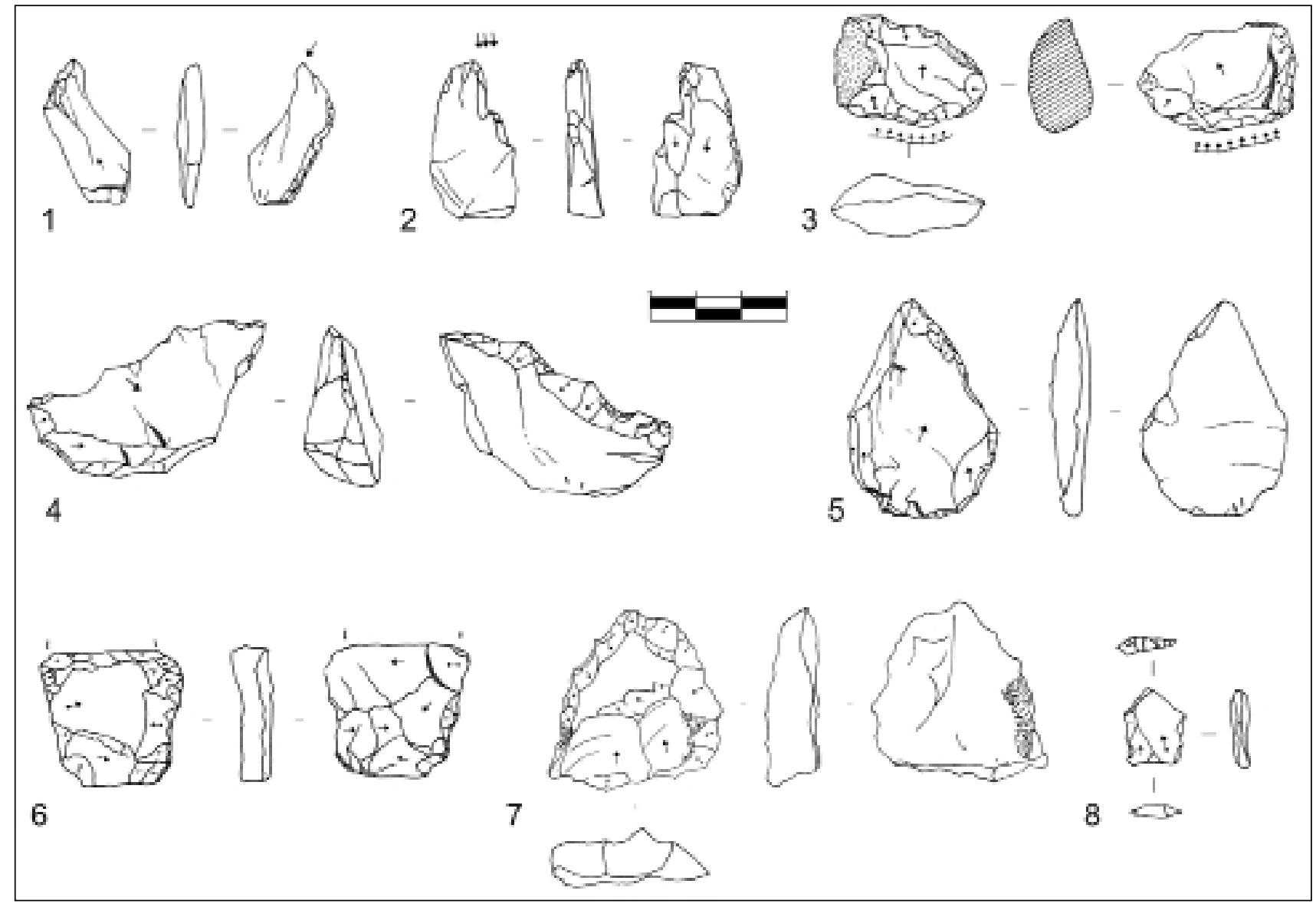

$\Delta$ Figura 9. Grupo de retocados. 1-2: buriles en cuarzo y sílex. 3 y 6: ejemplos de reciclaje: denticulado en cuarzo sobre núcleo bipolar, y raedera sobre fragmento mesial de foliáceo en cuarcita de grano fino. 4: denticulado. 5: punta en cuarcita. 7: raedera en sílex. 8: Truncadura en cuarzo.

(Fig. 11 y 12), salvo una punta de base cóncava en silex (Fig. 11: 7). Algunos de los tipos de fractura identificados pueden relacionarse con su utilización como elementos de proyectil (Márquez 2004).

Junto a estas piezas aparecen otros elementos más toscos realizados en cuarcita de grano fino y argilitas, correspondientes a piezas en proceso de elaboración, abandonadas por accidentes durante la talla, similares a los documentados por ejemplo en los niveles del Solutrense de Las Caldas o en el valle de Almoinha (Maíllo 1999). Incluso, algunas formas finales son demasiado toscas en la estructuración de los retoques y sus proporciones morfológicas, lo que podría vincularse con actividades de aprendizaje (vg. Maíllo 1999). Sin embargo, existe un gran número de lascas en cuarcita de grano fino producto de procesos de adelgazamiento bifacial. Son lascas finas, con talones lineales $(16,3 \%)$ y marcados labios que indican la utilización del percutor elástico, y generalmente se encuentran fracturadas en su parte distal. Estas piezas nos marcan actividades centradas en la producción de foliáceos en el yacimiento, donde existe una especialización con respecto al uso de la cuarcita de grano fino para la fabricación de puntas de laurel y foliáceos, atestiguada en este caso tanto por los productos finales como por ele- mentos de configuración, similar a lo documentado en otros contextos cantábricos (especialmente asturianos, Rasilla y Santamaria 2005). La presencia de lascas Kombewa podría corresponderse con los momentos iniciales de la reducción de los soportes aportados en forma de grandes lascas.

\section{EL YACIMIENTO DE VALVERDE Y LA CUESTIÓN DE LA CONTINUIDAD/ DISCONTINUIDAD DEL POBLAMIENTO DEL NOROESTE PENINSULAR}

Las prospecciones arqueológicas desarrolladas en la depresión de Monforte de Lemos han llevado al descubrimiento de artefactos líticos en superficie y en contexto estratigráfico que abarcan desde el Paleolítico inferior hasta el superior, lo que apunta al carácter estratégico de la cuenca para la movilidad de los grupos de cazadores recolectores del NO peninsular (de Lombera et al. 2011; Rodríguez et al. 2008).

El yacimiento de Valverde es el que ofrece la mayor concentración de restos líticos. Desgraciadamente, la ausencia de un contexto estratigráfico cerrado y de evidencias orgánicas nos impiden obtener una datación absoluta de las 


\begin{tabular}{|c|c|c|c|c|c|c|c|c|c|}
\hline Tipos & Argilita & $\begin{array}{c}\text { Cristal de } \\
\text { roca }\end{array}$ & Cuarcita & $\begin{array}{l}\text { Cuarcita } \\
\text { grano fino }\end{array}$ & Cuarzo & Lidita & Sílex & Sílice & TOTAL \\
\hline B & & & & 1 & 4 & & 1 & & 6 \\
\hline$\%$ & & & & 16,67 & 66,67 & & 16,67 & & 4,55 \\
\hline $\mathrm{Bc}$ & & & & 1 & & & 1 & & 2 \\
\hline$\%$ & & & & 50,00 & & & 50,00 & & 1,52 \\
\hline BT & & 1 & & & & & & & 1 \\
\hline$\%$ & & 100,00 & & & & & & & 0,76 \\
\hline D11, D21 & & & 1 & 5 & 14 & & & & 20 \\
\hline$\%$ & & & 5,00 & 25,00 & 70,00 & & & & 15,15 \\
\hline D13, D23 & 1 & & & 1 & 5 & 1 & 1 & & 9 \\
\hline$\%$ & 11,11 & & & 11,11 & 55,56 & 11,11 & 11,11 & & 6,82 \\
\hline D24 & & & & & 1 & & & & 1 \\
\hline$\%$ & & & & & 100,00 & & & & 0,76 \\
\hline D12,D22 & 1 & & & & 1 & 1 & & & 3 \\
\hline$\%$ & 33,33 & & & & 33,33 & 33,33 & & & 2,27 \\
\hline $\mathrm{F}$ & 1 & & & 3 & 1 & 1 & & 1 & 7 \\
\hline$\%$ & 14,29 & & & 42,86 & 14,29 & 14,29 & & 14,29 & 5,30 \\
\hline G & 1 & 2 & & 5 & 6 & & 4 & & 18 \\
\hline$\%$ & 5,56 & 11,11 & & 27,78 & 33,33 & & 22,22 & & 13,64 \\
\hline LD & & 2 & & & 1 & & & & 3 \\
\hline$\%$ & & 66,67 & & & 33,33 & & & & 2,27 \\
\hline Otro & 2 & 1 & & 4 & 7 & & 1 & & 15 \\
\hline$\%$ & 13,33 & 6,67 & & 26,67 & 46,67 & 0,00 & 6,67 & & 11,36 \\
\hline$P$ & 1 & & & 3 & & 1 & 1 & & 6 \\
\hline$\%$ & 16,67 & & & 50,00 & & 16,67 & 16,67 & & 4,55 \\
\hline PD & & 1 & & & & & & & 1 \\
\hline$\%$ & & 100,00 & & & & & & & 0,76 \\
\hline $\mathrm{R}$ & 3 & 1 & 1 & 6 & 9 & 1 & 4 & & 25 \\
\hline$\%$ & 12,00 & 4,00 & 4,00 & 24,00 & 36,00 & 4,00 & 16,00 & & 18,94 \\
\hline $\mathrm{T}$ & & & & & 4 & & & & 4 \\
\hline$\%$ & & & & & 100,00 & & & & 0,03 \\
\hline U. Compuestos & & 1 & & & 5 & & & & 6 \\
\hline$\%$ & & & & & 83,33 & & & & 4,55 \\
\hline Indet & & & 3 & 1 & & 1 & & & 5 \\
\hline$\%$ & & & 60,00 & 20,00 & & 20,00 & & & 0,04 \\
\hline TOTAL & 10 & 9 & 5 & 30 & 58 & 6 & 13 & 1 & 132 \\
\hline$\%$ & 7,58 & 6,82 & 3,79 & 22,73 & 43,94 & 4,55 & 9,85 & 0,76 & \\
\hline
\end{tabular}

ム TABla 2. Relación de tipos primarios y secundarios del grupo de los denticulados según materias primas. Sólo se han considerado los retocados completos.

ocupaciones así como realizar inferencias sobre el número o carácter funcional de las mismas. El depósito se encuentra fuertemente alterado por las actividades agrícolas que han producido la movilización in situ de los materiales líticos. No obstante, el nivel de base identificado en los sondeos del corte y la Cata II, así como en las vertientes del monte de Valverde, se corresponde con un modelo de sedimentación en un ambiente frio, periglacial, y presenta facies semejantes a las que se observan en otras laderas de las montañas circundantes a la depresión de Monforte de Lemos. La industria lítica localizada a techo de dicho nivel podría indicar que las ocupaciones se situarian en los momentos finales o posteriores a unas condiciones de sedimentación periglacial. En este sentido, tanto las características tecno- tipológicas del conjunto lítico como el contexto sedimentario del yacimiento son coherentes con ocupaciones del Paleolítico superior. El modelo de gestión y explotación de los recursos líticos, el patrón de asentamiento y la presencia de cadenas operativas especializadas en la producción de soportes laminares y útiles foliáceos nos permiten adscribirlo específicamente al Solutrense, convirtiéndose así en la primera evidencia de este periodo en Galicia. La aparición de varios fragmentos de puntas de laurel, la generalización del retoque bifacial para las mismas y, muy especialmente, el ejemplar de base cóncava, permiten encuadrar este conjunto dentro del Solutrense superior cantábrico.

Para este periodo existen varios paralelos en el área cantábrica (vg. Cueto de la Mina, Aiztbitarte, Cueva del Conde, 


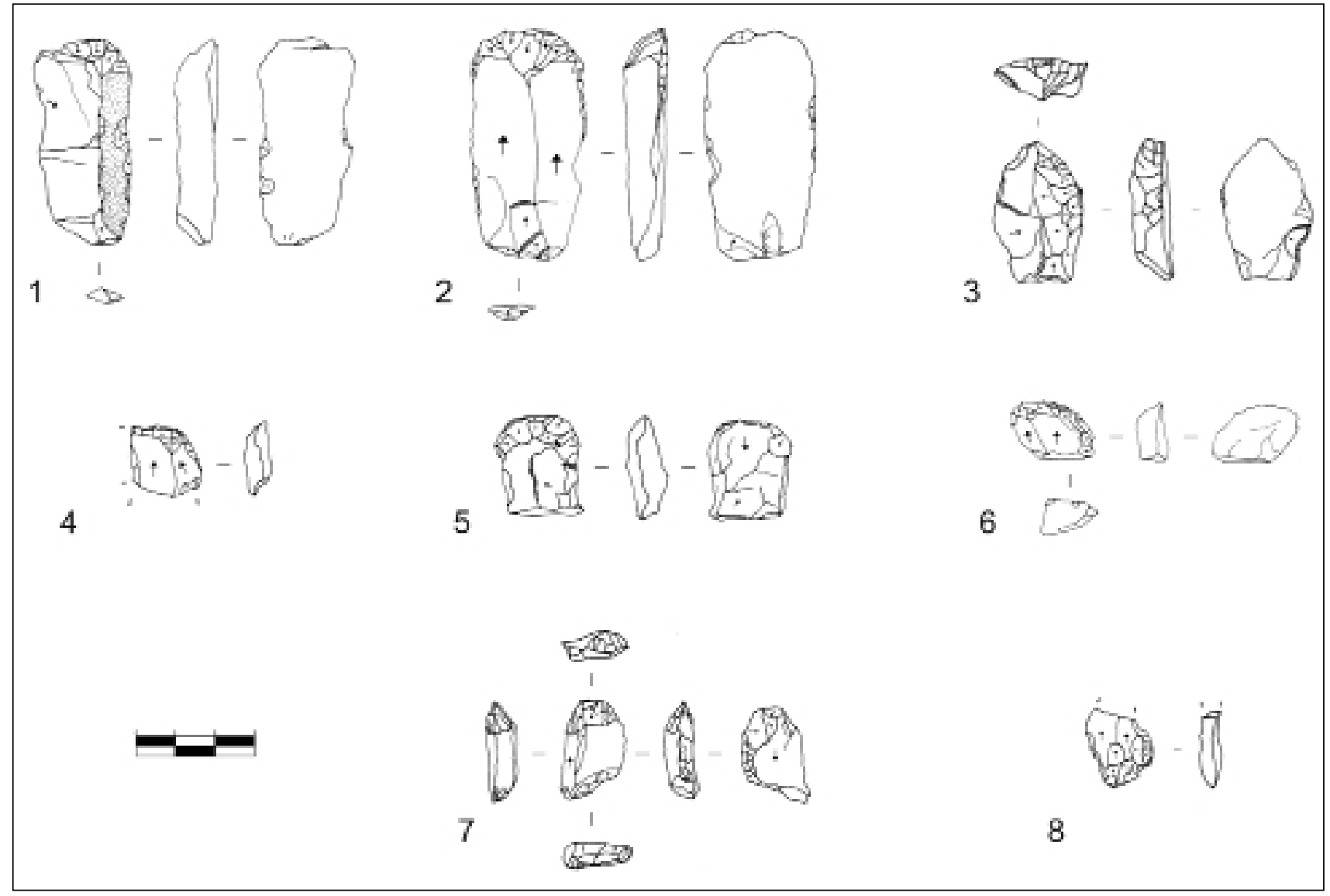

$\Delta$ Figura 10. Conjunto de raspadores. 1-2: cuarcita grano fino. 3: cuarzo. 4-7: sílex. 8: lasca en cuarzo.

Cueva del Mirón, Chufín, La Riera) (Rasilla y Strauss 2007; Strauss et al. 2011) donde el yacimiento de la cueva de Las Caldas se erige como la secuencia de referencia para el Cantábrico occidental (Corchón 1999). Las caracteristicas del conjunto lítico de Valverde son similares a las de los niveles 9-11 de la Sala I de Las Caldas, con un rol importante de las cuarcitas locales de buena calidad y de las puntas de laurel de base convexa y cóncava (Corchón 1995). Las dataciones radiométricas para estos niveles señalan una horquilla temporal entre el 20600-19500/19200 cal BC (Corchón 1999) que enmarcan estas ocupaciones del Solutrense superior entre un momento inicial caracterizado por la mayor presencia de humedad (niveles 11 y 12, interestadial IS2) y otro más riguroso, con evidencias de fauna fría (nivel 9, 12).

En este sentido, la adscripción al Solutrense superior del conjunto de Valverde nos permite barajar un marco cronológico para las ocupaciones en torno al $20000 \mathrm{BP}$, cubriendo así uno de los hiatos arqueológicos de la investigación del Paleolítico superior en Galicia (Fábregas y de Lombera 2010). De este modo, el yacimiento se erige como la primera evidencia de ocupaciones durante el Pleniglacial, abriendo la cuestión sobre la entidad del poblamiento en el noroeste peninsular durante este periodo.

Para el Pleniglacial würmiense, los análisis polínicos de los sistemas limnéticos del interior (Ramil et al. 2005,
2010) y depósitos marinos (Roucoux et al. 2005) permiten determinar la existencia de un clima relativamente húmedo en relación a otras áreas continentales, lo que favorece el dominio de las estepas herbáceas, restringiendo los elementos crioxéricos (Artemisia, Chenopodium, etc.) a las zonas más secas y continentales del interior (estepas de carácter semidesértico). Los valores arbóreos en los espectros polinicos muestran un dominio de Pinus, mientras las especies caducifolias se ven reducidas a porcentajes en torno al 5\%. En cambio, en las secuencias del litoral, si bien se aprecia una hegemonía del polen no arbóreo ( $>50 \%$ ) dominado por Poaceae con ciertos taxones arbustivos (Ericaceae), el polen arbóreo alcanza una mayor representación que en las zonas interiores (20\%), dominando el Quercus robur y Betula, mientras que Corylus, Alnus, Fraxinus y Salix mantienen curvas continuas (Ramil et al. 2010). De este modo, durante el Pleniglacial würmiense se manifiesta una dinámica diferente entre los paisajes fríos y relativamente húmedos del litoral y las condiciones un poco más secas en las Ilanuras y depresiones interiores, quedando las formaciones boscosas reducidas a aquellas zonas refugio o espacios topográficamente más favorables del litoral y la zona sublitoral (Ramil et al. 2005).

Por otro lado, los estudios en los fondos de las Rías Baixas (principalmente en la Ría de Vigo), muestran des- 


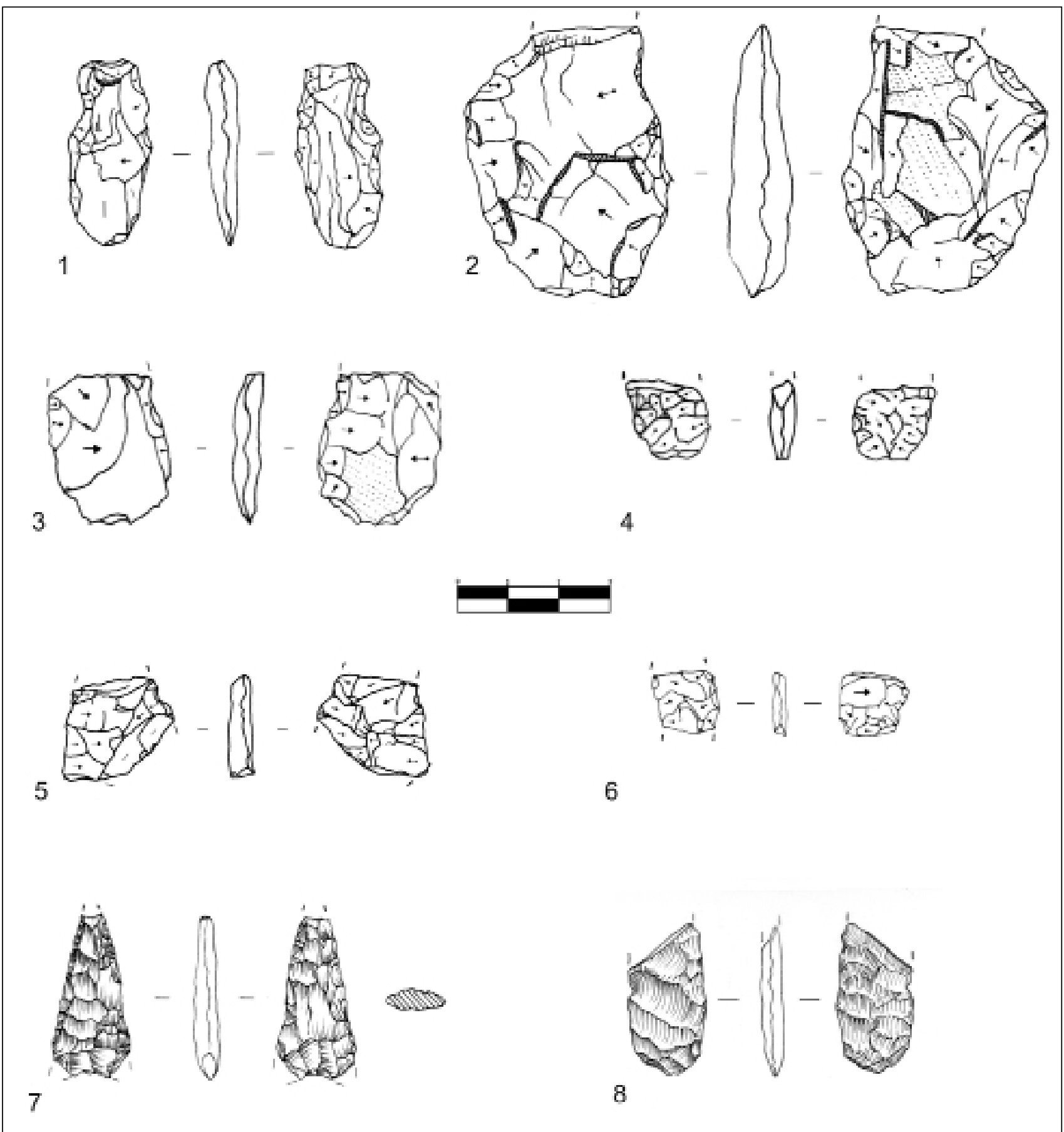

A Figura 11. Piezas con retoque plano y foliáceos. 1: lidita. 2-3: cuarcita de grano fino. 4: fragmento proximal de punta de base convexa en cuarzo. 5-6: fragmentos mesiales de puntas en argilita. 7: punta de base cóncava en sílex. 8: fragmento de punta de base convexa en sílex (Dibujo: X. Constela).

censo de 100-140 metros respecto al nivel del mar actual entre los momentos finales del MIS3 y el LGM (Alonso y Pagés 2007; García et al. 2005), con retrocesos estimados de $10.2 \mathrm{~km}$ respecto a la línea litoral actual (Cano et al. 1997). La estabilidad de esta etapa, aunque con pequeñas fluctuaciones, perduraría hasta el 15-14 ka BP (Alonso y Pagés, 2007; García y García, 2005), posibilitando el hábitat en los fondos de valle de las actuales rías gallegas, caracterizados por la presencia de zonas encharcadas y pantanosas en aquellas áreas poco drenadas, quizás con pequeños reductos boscosos (Alonso y Pagés, 2007). Por otro lado, esta regresión de la línea de costa conduciría a la formación de nuevas vías de comunicación litorales en sentido E-O y N-S que favorecerian el tránsito de especies animales y vegetales (y grupos humanos) desde Portugal y la cornisa cantábrica (Grandal et al. 1997).

A pesar de que la incidencia de los procesos morfogenéticos en los depósitos costeros y continentales siguen 
Arturo de Lombera Hermida, Xose-Pedro Rodríguez Álvarez, Xose Rabuñal Gayo, Alicia Ameijenda Iglesias, Fátima Martínez Gómez, Miguel Soares Remiseiro, Augusto Pérez Alberti y Ramón Fábregas Valcarce

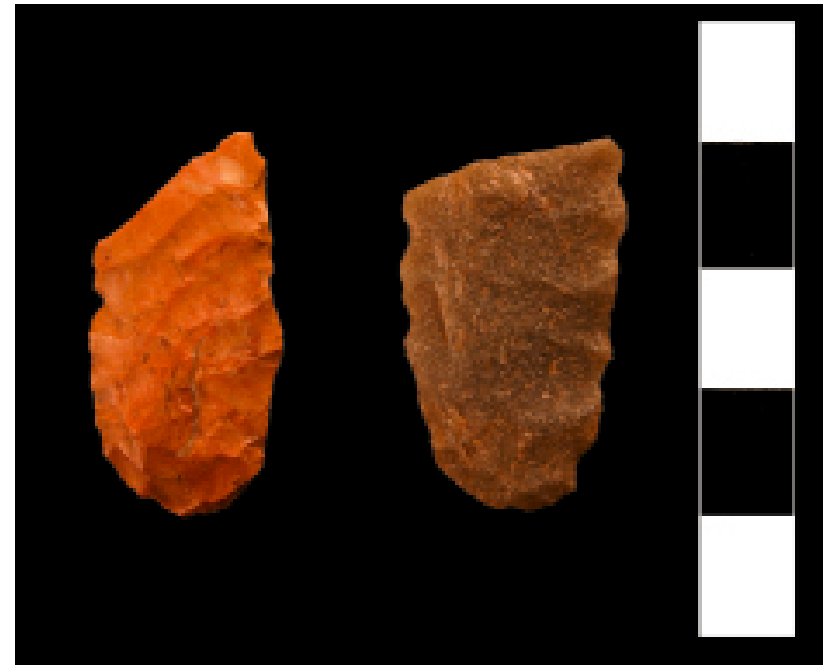

A Figura 12. Fragmentos de puntas de base convexa en sílex y cuarcita de grano fino.

marcando la rigurosidad del clima en el Pleistoceno superior final (Ameijenda et al. 2010; Pérez-Alberti et al. 2009; Blanco et al. 2002; Costa et al. 2007), los espectros polínicos (Jalut et al. 2010; Ramil et al. 2010; Roucoux et al. 2005), las secuencias edáficas sedimentarias en Caamaño I y Moreira (Trenhaile et al. 1999; Pérez-Alberti et al. 1999) y la rápida colonización posterior de la mayor parte del NO Ibérico protagonizada por los bosques caducifolios durante el Tardiglacial (Muñoz et al. 2004) sugieren una menor rigurosidad del clima en este periodo con respecto a otras áreas peninsulares, así como la importancia de las zonas refugio.

En las montañas del interior se constata una fuerte incidencia del glaciarismo con formas glaciares y periglaciares que alcanzan cotas relativamente bajas (ca. 900 m s.n.m.) en las sierras orientales (Ancares, Courel, A Queixa) (PérezAlberti y Valcárcel 1998; Valcarcel y Pérez-Alberti 2002). Si bien para esta región durante las etapas de mayor rigurosidad se establece la línea de nieves perpetuas en torno a los 800-900 m s.n.m. con descensos importantes de la temperatura media anual (Kulheman et al. 2008; Valcarcel et al. 2009), las dataciones de los depósitos sedimentarios postglaciares de Pías (ca. 31-27 ka BP), sitúan el máximo avance de los hielos (Last Ice Maximum Extent) en momentos anteriores al estipulado globalmente, probablemente anterior al 30000 BP (Pérez-Alberti et al. 2011), persistiendo glaciares de menor entidad en montañas a mayores alturas durante el 20-18 ka BP (Fase de Glaciares individualizados) (Pérez-Alberti y Valcárcel, 1998).

El único registro faunístico datado que conservamos de este periodo en la zona interior procede del nivel $\mathrm{V}$ del perfil sur de Cova da Valiña, con dos fechas radiocarbónicas entre el $21870 \pm 780 / 710 \mathrm{BP}(\mathrm{GrN}-20835)$ y $16420 \pm 70 \mathrm{BP}(\mathrm{GrN}-$ 2836) (Ramil y Fernández, 1996), aunque la indefinición del contexto y los valores algo discordantes cuestionan la fiabilidad de las mismas (ver Fábregas y de Lombera 2010;
Fernández 2000: 109). No obstante, a tenor de sus características de fosilización, los restos de reno recuperados en este yacimiento durante la revisión superficial de 1964 son ahora adscritos a dicho nivel V (Fernández 2000), abundando así en su carácter frío. La aparición de restos de Elephas primigenius en Buxán, podría relacionarse con este periodo de mayor rigurosidad climática (Torre 1962), análogos a los hallazgos similares en otras cavidades cantábricas (Las Caldas, Cueto de la Mina, Corchón, 1999: 21-22), aunque la ausencia de dataciones absolutas nos obliga a ser cautos al respecto.

En resumen, los datos geomorfológicos y los análisis polínicos de los depósitos costeros y glaciares del NO peninsular remarcan la fuerte influencia oceánica, que le confiere un carácter más húmedo y menos riguroso durante el LGM que el documentado en otras regiones continentales (Jalut et al. 2010; Pérez et al. 2011; Ramil et al. 2010; Roucoux et al. 2005), marcando la existencia de una zona refugio circunscrita al área litoral y prelitoral (Ramil et al. 2005). Pero proxies paleoclimáticos señalan a los valles del Miño y del Sil $y$, en particular, a la depresión de Monforte de Lemos cuyo fondo de valle se alza a 290 m s.n.m., como zonas refugio de interior con unas condiciones de temperatura y humedad similares a la del área litoral, aunque caracterizados por una marcada amplitud térmica entre los meses de invierno y verano (Valcárcel et al. 1998). La depresión de Monforte de Lemos se convierte así en un enclave estratégico: la vía de comunicación natural con el océano Atlántico es a través del valle del río Miño, mientras que la sucesión de depresiones terciarias del hinterland gallego (Santanach 1994), circundando las sierras orientales a cotas bajas, conformarian la ruta natural hacia la costa Cantábrica (de Lombera et al. 2011).

Aunque el contexto del yacimiento de Valverde nos impide profundizar sobre las condiciones paleoambientales de las ocupaciones solutrenses, el marco paleoclimático para el LGM, sensu lato, señala a las depresiones terciarias como posibles áreas refugio. En este sentido, la presencia de grupos de cazadores recolectores en la depresión monfortina podría interpretarse como fruto de la movilidad logística y estacional de los grupos, con incursiones realizadas hacia el interior del territorio en los periodos de mayor benignidad climática desde las zonas y valles refugio del litoral, similar al patrón documentado en el Cantábrico donde los yacimientos de mayor entidad se encuentran en las zonas bajas costeras o valles más resguardados como el Nalón (Straus et al. 2011; Corchón 1999). El emplazamiento estratégico de Valverde, así como las evidencias de fabricación y uso de las puntas foliáceas en el conjunto lítico remarcarian el carácter cinegético de las ocupaciones, aunque la presencia de procesos de talla in situ, así como de ciertos útiles (raspadores, buriles, denticulados, etc.), apuntan también hacia la existencia de actividades de carácter más doméstico. No 
obstante, la ausencia de un contexto estratigráfico seguro nos impide concretar mejor la entidad, número y funcionalidad específica de estas ocupaciones.

Durante el Solutrense superior se produce una fragmentación de los territorios de la Península Ibérica, siendo uno de los principales marcadores territoriales para el caso franco-cantábrico la punta de base cóncava (Rasilla y Santamaría 2005). La presencia de este útil en el conjunto lítico de Valverde, así como la probable procedencia cantábrica de algunos tipos de silex identificados (de Lombera et al. e.p.) nos marcan claros vínculos para esta ocupación con la dinámica solutrense cantábrica.

Por otro lado los esquemas técnicos de explotación laminar de los prismas de cuarzo y la aplicación de la técnica bipolar suponen la continuación de esquemas de talla atestiguados en el $\mathrm{NO}$ al menos desde momentos gravetienses, como el nivel 1 de Cova Eirós (Rodríguez et al. 2011) y en los yacimientos de Olga Grande 4 y 14 y Cardina I, en el valle del Côa (Aubry et al., 2009). La presencia de cristal de roca, normalmente un recurso local, no es ajena al mundo solutrense cantábrico y del norte de Cataluña, aunque suele ser minoritaria (vg, Las Caldas, Morín, Reclau Viver). Sin embargo, en los yacimientos del NO de la Península lbérica el cristal de roca juega un papel suplementario al sílex, rol que perdura hasta los momentos finales del Paleolítico superior (de Lombera y Rodríguez 2010) y que supone una estrategia de adaptación a los condicionantes litológicos del territorio. Los yacimientos contemporáneos del valle del Côa (Fase 5b) muestran estos métodos de producción laminar junto con elementos propios del Cantábrico como las puntas de muesca (Olga Grande 4 y 14) (Aubry 2009: 354). La convivencia de estos ejemplares en otras zonas portuguesas (vg. Correiro-Mor) nos habla de la existencia de relaciones entre ambos territorios peninsulares durante el Solutrense superior (Rasilla y Llana 1995; Corchón 2008), en el marco de la amplia movilidad de materias primas documentada en estos territorios (Corchón et al. 2009), si bien en los asentamientos del Côa los sílex foráneos muestran una vinculación más directa con la Estremadura portuguesa y el Sistema Central (Aubry et al. 2012). La presencia de sílex foráneo en el yacimiento de Valverde debe entenderse dentro de esos esquemas de movilidad e intercambios.
La práctica ausencia de yacimientos adscritos al Pleniglacial en el NO peninsular (nivel 1 de Cova Eirós y la base del talud de Valdavara 1/2) hacía pensar en la escasa densidad de población del territorio durante el LGM, sensu lato, que no se incrementaría hasta bien entrado el Tardiglacial (Fábregas y de Lombera 2010). Sin embargo, el descubrimiento del yacimiento de Valverde muestra la presencia de grupos de cazadores recolectores por los valles de interior durante los momentos más rigurosos de ese periodo. Si bien esta ocupación debe ser entendida dentro de la movilidad estacional y logística de estas comunidades, existen ciertos indicios que permitirian aseverar la existencia de un poblamiento más 0 menos continuado en el NO durante el Paleolítico superior, similar al observado en la zona del Côa o cornisa cantábrica. Por un lado, se constata la pervivencia de esquemas de talla especializados en la explotación del cristal de roca (laminar y bipolar) que se documentan ya en el Gravetiense y que perduran hasta los momentos epipaleolíticos. Por otro, el modelo de explotación de los recursos líticos identificado en el yacimiento de Valverde, definido por el descubrimiento y explotación de afloramientos silíceos locales, refleja un alto grado de conocimiento de la oferta litológica del territorio y de inversión de tiempo y energía por parte de estos grupos en el abastecimiento y búsqueda de los recursos abióticos, modelo que continúa para los yacimientos del Tardiglacial. De tal modo, la ocupación de Valverde puede reflejar la existencia de un poblamiento durante el Pleniglacial de mayor entidad que el hasta ahora pensado, quizás reducido a las áreas refugio del litoral durante los momentos más rigurosos. La ausencia de yacimientos superopaleolíticos en la costa gallega ahonda en la necesidad de focalizar las investigaciones sobre estas regiones tradicionalmente ajenas a los estudios del Paleolítico superior gallego.

\section{AGRADECIMIENTOS}

Las intervenciones en el yacimiento de Valverde se enmarcan dentro del proyecto de investigación HAR/201021786 del Ministerio de Economía y Competitividad. A. L-H es beneficiario de una ayuda predoctoral de la Fundación Atapuerca. Dibujos: Fátima Martínez.

\section{BIBLIOGRAFÍA}

ALoNso, A. y PAGÉS, J. L. 2007: "Stratigraphy of Late Pleistocene coastal deposits in Northern Spain". Journal of Iberian Geology 33(2): 207-220.

AmeIJeNDA IglesiAS, A. 2011: "Geomorphology and Relative Chronology of the Human Occupations during the Pleistocene at the Basin of Monforte de Lemos (Lugo, Galicia)". En A. de Lombera Hermida y R. Fábregas Valcarce (eds..) To the West of Spanish Cantabria: the Palaeolithic Settlement of Galicia. Archaeopress, Oxford. British Archaeological Reports. BAR 2283: 81-92.
Ameijenda Iglesias, A., De Lombera Hermida, A., Pérez Albertl, A. y Rodriguez Álvarez, X. P. y Fábregas Valcarce, R. 2010: "Geomorphological and Geoarchaeological evolution of the Monforte de Lemos Basin (Galicia, Spain). Erosion phases and post-depositional processes in NO Iberia " Estudos do Quaternário 6: 5-22.

AuBRY, T. (ed.) 2009: 200 séculos da história do Vale do Côa: incursões na vida quotidiana dos caçadores-artistas do Paleolítico. Trabalhos de Arqueologia, 52. IGESPAR, IP, Lisboa.

AubrY, T., Luis, L., MANGAdo LLACH, X. y MatiAS, H. 2012: "We will be known by the tracks we leave behind: Exotic lithic raw materials, mobility 
Arturo de Lombera Hermida, Xose-Pedro Rodríguez Álvarez, Xose Rabuñal Gayo, Alicia Ameijenda Iglesias, Fátima Martínez Gómez, Miguel Soares Remiseiro, Augusto Pérez Alberti y Ramón Fábregas Valcarce

and social networking among the Côa Valley foragers (Portugal)". Journal of Anthropological Archaeology 31 (4): 528-550.

Aubry, T., Mangado Llach, X. y Davide Sampaio, J. 2009: "Os artefactos: reconstituição da funcionalidade e da dinâmica de formação dos sítios. Estudo do aprovisionamento em matérias-primas". En T. Aubry (ed.) 200 séculos da história do Vale do Côa: incursões na vida quotidiana dos caçadores-artistas do Paleolítico. Trabalhos de Arqueologia, 52. IGESPAR, IP, Lisboa. 52: 131-170.

Blanco Chao, R., Costa Casals, M., Martinez Cortizas, A., Pérez Alberti, A. y VÁzouez PAZ, M. 2002: "Holocene evolution on Galician coast (NW Spain): an example of paraglacial dynamics". Quaternary International 93-94: 149-159.

Bouza Brey, F. y Álvarez Blázquez, J. M. (1952): Industrias paleolíticas do Baixo Miño (Concellos de A Guardia, O Rosal, Tomiño e Oya). TrabaIhos de Antropología e Etnología XIV (1-2): 5-65.

Cano Pan, J. A., Fumanal, M. P., Ferrer, C., Usera, J., A. M. Blázouez y OLMO, J. 1997: "Evolución de la costa meridional de Galicia durante el Cuaternario Superior". En J. Rodríguez Vidal (ed.) Cuaternario Ibérico: 33-46.

CHELIDONIO, G. 1990: "Preliminary approach to quartz crystals technology and its meaning as "Environmental Translation"". Le Silex de sa genèse à l'outil. Actes du Vo Colloque international sur le Sílex. Cahiers du Quaternaire 17.

Conde Ruiz, C., BAena, J. y CARRIón, E. 2000: «Los modelos de explotación de los recursos líticos durante el Pleistoceno de la región de Madridn. SPAL 9: 145-166.

CoRChón, M. S. 1995: "La Cueva de las Caldas (Priorio, Oviedo). III. Resultados preliminares de la excavaciones (Campañas 1991-1994)". Excavaciones Arqueológicas en Asturias 1991-94: 45-60.

- 1999: "Solutrense y Magdaleniense del oeste de la Cornisa Cantábrica: Dataciones 14C (calibradas) y marco cronológico". Zephyrvs LII: 3-32.

- 2002: "El Tardiglaciar y la transición al Postglaciar en la Meseta norte española: una revisión de síntesis". Zephyrvs LV: 85-142.

- 2008: "El Solutrense y el arte rupestre en Portugal. Reflexiones acerca de la obra de 0 . da Veiga Ferreira y su proyección actual" En Homenagem a Octávio da Veiga Ferreira. Cámara Municipal de Oeiras, Oleiras. 16: 183-234.

CoRchón, M. S. y CARdoso, J. L. 2005: "Reflexiones sobre el Solutrense portugués: A propósito de la industria Paleolítico superior de Correiro-Mor (Loures)". Zephyrvs LVIII: 89-110.

Corchón, M. S. ; TARriño, A. y Martinez Quintana, J. 2009: "Mobilité, térritoires et relations culturelles au début du Magdalénien moyen cantabrique: nouvelles perspectives". En F. Djindjian, J. Kozlowski y N. Bicho (eds.), Le concept de territoires dans le Paléolithique supérieur européen. Proceedings of the XV World Congress UISPP (Lisbon, 4-9 September 2006): 217-230).

Costa Casals, M., Blanco Chao, R., Martinez Cortizas, A. y Pérez Alberti, A. 2007-2008: "Los Episodios Heinrich en la costa de Galicia (NW de la Península lbérica). Un análisis a través de los sedimentos continentales". Territoris 7: 39-53.

De La Peña Alonso, P. 2011: "Sobre la identificación macroscópica de las piezas astilladas: propuesta experimental". Trabajos de Prehistoria 68(1): 79-98.

De La Peña Alonso, P. y Vega Toscano, G. 2012: "Flaking technology strategies in Early Upper Paleolithic levels from the Southeastern lberian Peninsula". En A. Pastoors y M. Peresani (eds.) Flakes not Blades: The role of Flake Production at the Onset of the Upper Palaeolithic in Europe. Wissenschaftliche Schriften des Neanderthal Museums 5: 51-68.

De La Torre, I., Benito Calvo, A., Arroyo, A., Zupancich, A. y Proffit, T. 2013: "Experimental protocols for the study of battered stone anvils from Olduvai Gorge (Tanzania)". Journal of Archeological Science 29(6): 639-665.

De Lombera Hermida, A. y Rodriguez Rellán, C. 2010: "Gestión y estrategias de abastecimiento de las materias primas locales (cuarzo, cuarcita y pizarra) en la Prehistoria del NW Peninsular". En S. Do-
mínguez-Bella, J. Ramos Muñoz, J. M. Gutiérrez López y M. Pérez Rodríguez (eds.) Minerales y rocas en las sociedades de la Prehistoria. Grupo de Investigación HUM-440. Universidad de Cádiz, Cádiz: 49-60.

De lombera Hermida, A., Vaquero Rodriguez, M., Alonso Fernández, S., Rodriguez Álvarez, X. P., Lazuén Fernández, T. y Fábregas Valcarce, R. 2008: "A cunca media no Miño dentro das ocupacións paleolíticas do NW peninsular" En E. Méndez Quintas (ed.) Homenaxe a Xose María Álvarez Blázquez (2). Estudos sobre Paleolítico. Instituto de Estudos Miñoranos, Gondomar: 321-346.

De Lombera Hermida, A., Rodriguez Álvarez, X. P., Fábregas Valcarce, R. y LazuÉn Fernández, T. 2011: "The Paleolithic settlement of the Monforte Basin (Lugo, Galicia)" En A. de Lombera Hermida y R. Fábregas Valcarce (eds.) To the West of Spanish Cantabria: the Palaeolithic Settlement of Galicia. Archaeopress, Oxford. British Archaeological Reports (BAR). 2283: 93-110.

De Lombera Hermida, A., Rodriguez Rellán, C. y Vaquero Rodriguez, M. e.p.: "El silex en el NW de la Península Ibérica. Un estado de la cuestión" En A. Tarriño (ed): SílEX: trazadores litológicos de larga distancia durante la Prehistoria de la Península lbérica. Burgos.

Delibes De Castro, G. y Dízz Martin, F. 2006: "UUna Meseta desolada? Estado actual de la investigación sobre el Paleolítico superior en las regiones interiores de la Península Ibérica" En G. Delibes de Castro y F. Díez Martín (eds.) El Paleolítico superior en la Meseta Norte española. Studia Archaeologica 94. Universidad de Valladolid, VaIladolid: 11-40.

Diez-Martin, F. 2000: El Poblamiento paleolítico en los páramos del Duero. Universidad de Valladolid, Valladolid.

Diez Martin, F., Sánchez Yustos, P., Dominguez Rodrigo, M. y Prendergast, M. 2011: "An experimental study of bipolar and freehand knapping of Naibor Soit quartz from Olduvai Gorge (Tanzania)" American Antiquity 76(4): 690-708.

Fabián García, F. 1986: "La industria lítica del yacimiento de La Dehesa en el Tejado de Béjar (Salamanca). Una industria de tipología magdaleniense en la Meseta Norte. Avance a su estudio". Numantia 2: 101-141.

- 1984-1985: "Los útiles de arista diédrica sobre primas piramidales o nódulos de cristal de roca (U.A.D.) en el yacimiento de la Dehesa, El Tejado de Béjar (Salamanca). Estudio morfotécnico". Zephyrvs XXXVII-XXXVIII: 115-124.

Fábregas Valcarce, R. 1991: Megalitismo del Noroeste de la Península Ibérica Tipología y secuencia de los materiales líticos. UNED, Madrid.

Fábregas Valcarce, R. y De Lombera Hermida, A. 2010: "El Paleolítico superior en Galicia a la luz de las últimas investigaciones. En X. Mangado (Eds..) Paleolítico superior peninsular. Novedades del siglo XXI. Homenaje al Profesor Javier Fortea. Monografies SERP. Universitat de Barcelona, Barcelona. 8: 255-270.

Fábregas Valcarce, R., Lazuén Fernández, T., De lombera Hermida, A., Peña Alonso, J. A., Pérez Alberti, A., Rodriguez Álvarez, X. P., Rodriguez ReLLÁN, C. y TerRadillos Bernal, M. 2007: "Novos achados paleolíticos no interior de Galicia. A Depresión de Monforte de Lemos e as súas industrias líticas". Gallaecia 26: 7-33.

Fábregas Valcarce, R., Alonso Fernández, S., Lazuén Fernández, T., De Lombera Hermida, A., Pérez Alberti, A., Rodriguez Álvarez, X. P., Rodriguez Rellán, C., Terradillos Bernal, M., Serna González, M. R. y Vaquero Rodriguez, M. 2008: "Aportacións ó estudo da Prehistoria da cunca media do Miño. Os asentamentos en cova e ó aire libre". Gallaecia 27: 63-88.

Fábregas Valcarce, R., Alonso Fernández, S., Ameijenda, A., Grandal d’Anglade, A., Lazuén Fernández, T., De lombera Hermida, A., Pérez Alberti, A., Pérez Rama, M., Rodriguez Álvarez, X. P., Rodriguez Rellán, C., Serna González, M. R., Terradillos Bernal, M. y VAquero Rodriguez, M. 2009: "Novos resultados das intervencións arqueolóxicas no sur lucense. Os xacementos paleoliticos da Depresión de Monforte (Monforte de Lemos), Cova Eirós (Triacastela) e Valdavara (Becerreá)". Gallaecia 28: 9-32. 
Fábregas Valcarce, R., Alonso Fernández, S., Amejuenda Iglesias, A., Grandal D’Anglade, A., lazuén Fernández, T., De lombera Hermida, A., Pérez Alberti, A., Pérez Rama, M., Rodriguez Álvarez, X. P., Serna González, M. R. y Vaquero Rodriguez, M. 2010: "Completando o mapa. Novas datacións absolutas para o Paleolítico e Mesolítico do interior galego". Gallaecia 29: 5-28.

Fábregas Valcarce, R., Alonso Fernández, S., Ameijenda Iglesias, A., Fernández Marchena, J., Grandal D’Anglade, A., Lazuén Fernández, T., De Lombera Hermida, A., Pérez Rama, M., Rodriguez Álvarez, X. P., Vaquero Rodriguez, M. y Veiga MoAres, A. 2011: "Variabilidade das ocupacións paleolíticas na cunca media do Miño". Gallaecia 30: 5-27.

Fernández Rodriguez, C. 2000: Los macromamíferos en los yacimientos arqueológicos del Noroeste Peninsular: un estudio económico. Tesis Doctoral. Dpto. Historia I. Universidade de Santiago de Compostela. Santiago de Compostela.

Garcia Garcia, A., Garcia GIL, S. y VILAS, F. 2005: "Quaternary evolution of the Ría de Vigo, Spain". Marine Geology 220: 153-179.

García Gazólaz, J. y Velaz CiáurRIZ, D. 1997: "La industria lítica tallada de las primeras comunidades neolíticas en la cuenca de Pamplona (Navarra): el caso del cristal de roca". Cuadernos de Arqueología 5: 7-29.

Grandal D’Anglade, A., López González, F. y Vidal Romaní, J. R. 1997: "Condicionantes en la distribución de macromamíferos en Galicia (NW Peninsular lbérica) durante el Cuaternario superior". Cadernos Laboratorio Xeolóxico de Laxe 22: 43-66.

Jalut, G., Turu I Michels, V., Dedoubat, J.-J., Otto, T., Ezouerra, J., Fontugne, M., Belet, J. M., Bonnet, L., De Celis, A. G., Redondo-Vega, J. M., VIDAL-Romani J. R. y SANTOS, L. 2010: "Palaeoenvironmental studies in NW Iberia (Cantabrian range): Vegetation history and synthetic approach of the last deglaciation phases in the western Mediterranean". Palaeogeography, Palaeoclimatology, Palaeoecology 297(2): 330-350.

KLARIC, L. 2009: "Les systèmes de production de supports d'armatures et leur place dans la gestion des ressources lithiques: une voie privilégiée pour la compréhension des societés gravettiennes de la Vallée du Côa". En T. Aubry (ed.) 200 séculos da história do Vale do Côa: incursoes na vida quotidiana dos caçadores-artistas do Paleolítico. IGESPAR, IP, Lisboa: 247-255.

Kuhlemann, J., Rohling, E. J., KubiK, P., IVY-OCHS, S. y KUCERA, M. 2008: "Regional Synthesis of Mediterranean Atmospheric Circulation During the Last Glacial Maximum". Science 321: 1338-1340.

López CoRdeIRO, M. M. 2002: "Ocupación de espacios graníticos en la Sierra de Xistral: El área arqueológica de Nordés (Valadouro, Lugo)". Gallaecia 21: 61-86.

Llana Rodriguez, C., Martinez Cortizas, M. y Ramil Rego, P. 1992: "Algunas consideraciones acerca de la estratigrafía y del marco temporal para los yacimientos al aire libre del Paleolitico Final y Epipaleolitico en Galicia". Zephyrvs XLIV-XLV: 155-166.

Maillo Fernández, J. M. 1999: "Esquemas operativos y conocimiento técnico: el caso del yacimiento solutrense de Vale Almoinha (Torres Vedras, Portugal)". Espacio, Tiempo y Forma, Serie I, Prehistoria y Arqueología 12: 185-214.

MÁrouez MoRA, B. 2004: "Los análisis traceológicos como forma de reconstruir las actividades prehistóricas: el caso de la caza". Homenaje a Emiliano Aguirre. Museo Arqueológico de Alcalá de Henares, Alcalá de Henares: 301-311.

Muñoz Sobrino, C., Ramil-Rego, P. y Gómez-Orellana, L. 2004: "Vegetation of the Lago de Sanabria area (NW Iberia) since the end of the Pleistocene: a palaeoecological reconstruction on the basis of two new pollen sequences". Veget. Hist. Archaeobot. 13:1-22.

NoVIKOV, V. P. y RADILILOVSKY, V. V. 1990: "Quartz anisotropy in Stone-Age artifacts of the Hissar". Le Silex de sa genèse à l'outil. Actes du Vo CoIloque international sur le Sílex. Cahiers du Quaternaire 17: 593-598.

OLmo SANZ, A. 1985: "Estudio Geológico-sedimentario de las cuencas terciario-cuaternarias de Monforte de Lemos, Maceda y Quiroga". Cadernos Laboratorio Xeolóxico de Laxe 10: 83-93.
Pérez Alberti, A. y Valcárcel Díaz, M. 1998: "Caracterización y distribución espacial del glaciarismo en el noroeste de la Península lbérica". En A. Gomez Ortiz y A. Pérez Alberti (eds.): Las Huellas Glaciares de las Montañas Españolas. Servicio de Publicacions da Universidade de Santiago de Compostela: 17-54.

Pérez Alberti, A., Costa Casals, M. y Martinez Cortizas, A. 1999: "Nuevas aportaciones al conocimiento del Cuaternario reciente en la costa atlántica de Galicia". Geoarqueología i Quaternary litoral. Memorial María Pilar Fuman. Universitat de Valencia. Valencia: 381-390.

Pérez Alberti, A., Díaz, M. V., Martini, I. P., Pascucci, V. y Andreucci, S. 2011: "Upper Pleistocene glacial valley-junction sediments at Pias, Trevinca Mountains, NW Spain". En I. P. Martini, H. M. French y A. Pérez Alberti (Eds..) Ice-Marginal and Periglacial Processes and Sediments. Geological Society. Special publication 354. London: 93-110.

Pérez Alberti, A., Blanco Chao, R., Otero Otero, M., Macias Garcia, I. y López BeDoYA, J. 2009: "Cambios ambientais detectados na costa de Galicia durante o Plistoceno e Holoceno e dinámica actual" En V. Pérez Muñuzuri, M. Fernández Cañamero y J. L. Gómez Gesteira (eds.) Evidencias e Impactos do cambio climático en Galicia. Xunta de Galicia. Consellería de Medio Ambiente e Desenvolvemento Sostible, Santiago de Compostela: 425-454.

Ramil Rego, E. y Ramil Soneira, J. 1996: "El fin de los tiempos glaciares en Galicia. Magdaleniense y Epipalolítico" En R. Fábregas Valcarce (ed.) Os primeiros poboadores de Galicia: O Paleolítico. Edicións do Castro, Sada. 73: 117-147.

Ramil Rego, P. y Fernández Rodriguez, C. 1996: "Marco cronológico y paleoambiental de la ocupación paleolítica en el NW Ibérico" En R. Fábregas Valcarce (Eds.) Os primeiros poboadores de Galicia: 0 Paleolítico. Edicións do Castro, Sada. 73: 165-192.

Ramil Rego, P., Iriarte, M. J., Muñoz Sobrino, C. y Gómez Orellana, L. 2005: "Cambio climático y dinámica temporal del paisaje y de los hábitats en las ecorregiones del NW de la Península lbérica durante el Pleistoceno superior". Munibe 57: 537-551.

Ramil Rego, P., Gómez Orellana, L. y Muñoz Sobrino, C. 2010: "Cambio climático durante el último ciclo glaciar-interglaciar en el NW lbérico" En Ana M. S. Bettencourt, M. Isabel Caetano Alves \& Sérgio Monteiro-Rodrigues (eds.), Variações Paleoambientais e Evolução Antrópica no Quaternário do Ocidente Peninsular/ Paleoenvironmental Changes and Anthropization in the Quaternary of Western Iberia. Braga, Associação Portuguesa para o Estudo do Quaternário (APEO) e Centro de Investigação Transdisciplinar Cultura, Espaço e Memória (CITCEM): 23-38.

RASILLA VIVES, M. dE LA y SANTAMARIA, D. 2005: "Tecnicidad y territorio: las puntas de base cóncava del Solutrense cantábrico". Munibe 57(2): 149-158.

RASILla VIVES, M. DE LA y Straus, L. G. 2007: "El poblamiento en la región cantábrica en torno al último máximo glacial: Gravetiense y Solutrense" En M. A. Fano (ed.) Las Sociedades del Paleolitico en la Región Cantábrica, Bilbao. Kobie, Anejo, 8: 209-242.

RASILLA VIVES, M. DE LA y LLANA, C. 1995: "Del Solutrense en la Península Ibérica: el Solutrense en Portugal y los inicios del Solutrense". Trabalhos de Antropologia e Etnologia 30 (4): 89-103.

Rodriguez Álvarez, X. P., De Lombera Hermida, A., Fábregas Valcarce, R. y LAZUÉn Fernández, T. 2011: "The Upper Pleistocene site of Cova Eirós (Triacastela, Lugo, Spain)" En A. de Lombera Hermida y R. Fábregas Valcarce (eds.) To the West of Spanish Cantabria: the Palaeolithic Settlement of Galicia. BAR International series 2283, Oxford: 123-133.

Rodriguez Álvarez, X. P., Fábregas Valcarce, R., Lazuén Fernández, T., De Lombera Hermida, A., Pérez Alberti, A., Peña Alonso, J. A., Rodriguez Rellán, C., Terradillos Bernal, M., Ameijenda, A. y Rodriguez Álvarez, E. 2008: "Nuevos yacimientos paleolíticos en la Depresión de Monforte de Lemos (Lugo, Galicia, España)". Revista Cuaternario y Geomorfología 22(3-4): 71-92.

Rodriguez Relán, C. 2006: "Industria lítica del yacimiento Calcolítico de Lavapés (Cangas de Morrazo, Pontevedra)". Sautuola XII: 135-156.

Roucoux, K. H. ; De Abreu, L. ; Shackleton, N. J. y Tzedakis, P. C. 2005: "The response of NW Iberian vegetation to North Atlantic climate 
Arturo de Lombera Hermida, Xose-Pedro Rodríguez Álvarez, Xose Rabuñal Gayo, Alicia Ameijenda Iglesias, Fátima Martínez Gómez, Miguel Soares Remiseiro, Augusto Pérez Alberti y Ramón Fábregas Valcarce

oscillations during the last 65 kyr". Quaternary Science Reviews 24: 1637-1653.

Santanach Prat, P. 1994: "Las Cuencas Terciarias gallegas en la terminación occidental de los relieves pirenaicos". Cadernos Laboratorio Xeolóxico de Laxe 19: 57-71.

Straus, L. G., González Morales, M., GutiérRez Zugasti, I. y Iriarte, M. J. 2011: "Further Solutrean evidence in El Mirón Cave (Ramales de la Victoria, Cantabria)". Munibe 62 (117-133).

Tapia, J., ArRizabalaga, Á., Iriarte, M. J. y Calvo, A. 2009: "El campamento gravetiense de Ametzagaina (Donostia, Pais Vasco). Un avance a su estudio arqueológico". Munibe 60: 99-115.

Torre Enciso, E. 1962: "Hallazgo de dos molares de Mamut (Elephas primigenius), en una cantera de Buxán, Lugo." Notas y comunicaciones del I.G.M.E. 65: 111-118.

Trenhalle, A. T., Pérez-Alberti, A., Martinez, A., Costa, M. y Blanco, R. 1999: "Rock coast inheritance: an example from Galicia, Northwestern Spain". Earth Surface Processes and Landforms 24: 605-621.

Valcárcel Díaz, M. y Pérez AlbertI, A. 2002: "Los campos de bloques en Montañas del Noroeste de la Península lbérica: génesis y significado paleoambiental" En E. Serrano y A. Garcia (Eds.) Periglaciarismo en montaña y altas latitudes. Universidad de Valladolid, Valladolid: 13-26.

Valcárcel Díaz, M., Blanco Chao, R., Martínez Cortizas, A. y Pérez Alberti, A. 1998: "Estimación de las paleotemperaturas en Galicia durante el último ciclo glaciar a partir de datos geomorfológicos y climáticos" En A. Gómez Ortiz y F. Salvador Franch (Eds.) Investigaciones recientes de la Geomorfología española, Barcelona: 767-770.

Valcárcel Díaz, M., Blanco ChaO, R. y feal-pérez, A. 2009: "Fases geocriológicas reconocidas en el NO de la Península lbérica durante el Pleistoceno Final a partir de los datos geomorfológicos: implicaciones en la modelización de las condiciones paleoambientales" En G. Flor Rodríguez, J. Gallastegui, G. Flor Blanco y J. Martín Llaneza (Eds.) Nuevas contribuciones al Margen Ibérico Atlántico. $6^{\circ}$ Simposio sobre el Margen Ibérico Atlántico. Universidad de Oviedo, Oviedo: 165-168.

Vaquero Rodriguez, M., Alonso Fernández, S., Fernández, C. A., Ameijenda Iglesias, A., Blain, H., Fábregas Valcarce, R., Gómez Merino, G., De Lombera Hermida, A., López-Garcia, J. M., Lorenzo Merino, C., Lozano, M., Rodriguez Rellán, C., Rosell Ardèvol J. y Serna González, M. R. 2009: "Nuevas dataciones radiométricas para el Paleolítico Superior en Galicia: La cueva de Valdavara (Becerreá, Lugo)". Trabajos de Prehistoria 66(1): 99-113.

VILLAR QUINTEIRO, R. 1991: "Algunas consideraciones sobre el tratamiento técnico de los cuarzos presentes en yacimientos del Paleolítico Superior de Galicia y Asturias. Características de estos soportes". GaIlaecia 12: 39-50.

- 1997: "El Paleolítico Superior y Epipaleolítico en Galicia". Zephyrvs L: 71-106. 